\title{
1 MeTIQ and olanzapine, despite their neurochemical impact, did not ameliorate performance in fear conditioning and social interaction tests in an MK-801 rat model of schizophrenia
}

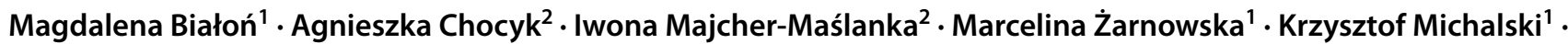 \\ Lucyna Antkiewicz-Michaluk ${ }^{1} \cdot$ Agnieszka Wąsik $^{1}$ (D)
}

Received: 18 September 2020 / Revised: 1 December 2020 / Accepted: 7 December 2020 / Published online: 6 January 2021

(c) The Author(s) 2021

\begin{abstract}
Background The aim of the present study was to evaluate the effect of 1MeTIQ on fear memory and social interaction in an MK-801-induced model of schizophrenia. The results obtained after administration of 1MeTIQ were compared with those obtained with olanzapine, an antipsychotic drug.

Methods Sprague-Dawley rats received a single injection of MK-801 to induce behavioral disorders. 1MeTIQ was given either acutely in a single dose or chronically for 7 consecutive days. Olanzapine was administered once. In groups receiving combined treatments, 1MeTIQ or olanzapine was administered 20 min before MK-801 injection. Contextual fear conditioning was used to assess disturbances in fear memory (FM), and the sociability of the rats was measured in the social interaction test (SIT). Biochemical analysis was carried out to evaluate monoamine levels in selected brain structures after treatment. Results Our results are focused mainly on data obtained from neurochemical studies, demonstrating that $1 \mathrm{MeTIQ}$ inhibited the MK-801-induced reduction in dopamine levels in the frontal cortex and increased the 5-HT concentration. The behavioral tests revealed that acute administration of MK-801 caused disturbances in both the FM and SIT tests, while neither 1MeTIQ nor olanzapine reversed these deficits.

Conclusion 1MeTIQ, although pharmacologically effective (i.e., it reverses MK-801-induced changes in monoamine activity), did not influence MK-801-induced social and cognitive deficits. Thus, our FM tests and SIT did not support the main pharmacological hypotheses that focus on dopamine system stabilization and dopamine-serotonin system interactions as probable mechanisms for inhibiting the negative symptoms of schizophrenia.
\end{abstract}

Keywords 1-Methyl-1,2,3,4-tetrahydroisoquinoline (1MeTIQ) - Olanzapine $\cdot$ MK-801 $\cdot$ Neurochemical studies $\cdot$ Contextual fear conditioning $\cdot$ Social interaction test (SIT)

Abbreviations
$\begin{array}{ll}\text { 1MeTIQ } & \text { 1-Methyl-1,2,3,4-tetrahydroisoquinoline } \\ \text { 3-MT } & \text { 3-Methoxytyramine } \\ \text { 5-HIAA } & \text { 5-Hydroxyindoleacetic acid } \\ \text { 5-HT } & \text { Serotonin } \\ \text { AFC } & \text { Auditory fear conditioning }\end{array}$

Agnieszka Wąsik

wasik@if-pan.krakow.pl

1 Department of Neurochemistry, Maj Institute of Pharmacology, Polish Academy of Sciences, Cracow, Poland

2 Laboratory of Pharmacology and Brain Biostructure, Department of Pharmacology, Maj Institute of Pharmacology, Polish Academy of Sciences, Cracow, Poland
CFC Contextual fear conditioning

COMT Catechol-O-methyltransferase

DOPAC 3,4-Dihydroxyphenylacetic acid

Fcx Frontal cortex

FM Fear memory

HPLC High-performance liquid chromatography

HVA Homovanillic acid

MAO Monoamine oxidase

NM Normetanephrine

NMDA $N$-Methyl-D-aspartate

SIT Social interaction test 


\section{Introduction}

Schizophrenia is a devastating mental illness that occurs in $1 \%$ of the population worldwide and may be characterized by emotional impairment, cognitive deficits, and social dysfunction [1]. According to cognitive deficits, abnormalities in associative memory processes may be observed in schizophrenic subjects [2].

Fear memory (FM) is crucial for predicting and avoiding aversive and dangerous events. Thus, appropriately functioning fear promotes survival and minimizes exposure to danger [3]. FM may be assessed by using Pavlovian fear conditioning when a conditional stimulus (CS), e.g., a tone, is followed by an unconditional stimulus (US), e.g., a foot shock in a specific training context. Thereby, animals develop a fear of both the tone and the training context, and the memory of that fear is measured by assessing freezing time, which is a natural, adaptive and speciesspecific reaction to threat $[4,5]$. Freezing behavior during CS presentation is taken as a measure of fear. The adaptive reaction of FM is disturbed in schizophrenia.

Social deficits are considered core negative symptoms in schizophrenia and are often the earliest symptoms of the illness $[6,7]$. To study social withdrawal, as a schizophrenia-related symptom, the social interaction test (SIT) is used as a screening tool after drug administration [8].

MK-801 is an NMDA receptor antagonist and is commonly used in animal models to mimic schizophrenialike behaviors [9]. MK-801 is reported to disturb working memory, memory consolidation, social interaction, contextual fear conditioning and prepulse inhibition [10-15].

Olanzapine is an atypical antipsychotic drug that is widely used in the treatment of schizophrenia [16]. Olanzapine affects many receptors, including the dopamine D2 receptor; serotonin 5-HT2A, 5-HT2C, and 5-HT6 receptors; adrenaline $\alpha 1$; histamine H1; and muscarine M1-M5 [17].

1-Methyl-1,2,3,4-tetrahydroisoquinoline (1MeTIQ) is an endogenous compound present in the mammalian brain, mainly in dopaminergic structures [18]. The bulk of evidence has shown that 1 MeTIQ has neuroprotective [19-22], antiaddictive [23] and anxiolytic-like properties [24]. As shown in previous studies, 1MeTIQ acts as a reversible inhibitor of monoamine oxidase (MAO); therefore, it is considered an antioxidative agent [22]. Early studies on tetrahydroisoquinolines indicated that they have neuroleptic-like properties [25], and our experiments confirmed that 1MeTIQ acts as a specific antagonist of agonistic conformations of dopamine receptors and may act as an inhibitory regulator that counteracts excessive stimulation of catecholaminergic systems [20, 26, 27].

Antipsychotic drugs show therapeutic efficacy in treating positive symptoms (e.g., hallucinations) of schizophrenia, but their effectiveness in treating negative symptoms and cognitive manifestations of the illness is limited [28]. Our earlier study showed that 1MeTIQ exhibits anxiolytic and procognitive properties in an animal model of schizophrenia [24, 29]; therefore, we decided to verify whether $1 \mathrm{MeTIQ}$ could eliminate negative symptoms or improve memory.

The aim of the present study was to evaluate the effect of 1 MeTIQ on neurochemical changes in monoamine levels within central nervous system components (specifically, the hippocampus and frontal cortex (Fcx) in a MK-801-induced model of schizophrenia. The results obtained after administration of $1 \mathrm{MeTIQ}$ were compared to those of olanzapine. Contextual fear conditioning was used to assess disturbances in FM, and sociability was measured in the SIT.

\section{Materials and methods}

\section{Animals and treatments}

All experimental procedures were approved by the Committee for Laboratory Animal Welfare and the Ethics Committee of the Institute of Pharmacology, PAS, in Krakow.

All experiments were conducted on male Sprague-Dawley rats with an initial body weight of 225-250 g. The animals were kept in standard polyacrylic cages (5 animals/ cage) with free access to water and standard laboratory food. Animals were kept at room temperature $\left(22^{\circ} \mathrm{C}\right)$ under an artificial light/dark cycle (12/12 h, light on at 7:00). A single injection of MK-801 $(0.3 \mathrm{mg} / \mathrm{kg}$, ip in the FM test; $0.1 \mathrm{mg} /$ $\mathrm{kg}$, sc in the SIT) was given to induce behavioral disorders. $1 \mathrm{MeTIQ}$ (25 mg/kg, ip) was given as a single dose or chronically for 7 consecutive days. Olanzapine ( $3 \mathrm{mg} / \mathrm{kg}$, ip) was administered once. In the combined groups, 1MeTIQ or olanzapine was administered $20 \mathrm{~min}$ before MK-801 injection. The last dose of $1 \mathrm{MeTIQ}$ in chronic treatment was given on the day of the behavioral test. Control rats were treated with vehicle $(0.9 \% \mathrm{NaCl})$. Doses of the drugs were based on our previous experience (1MeTIQ) or the literature (MK-801 and olanzapine). Animals were divided into eight groups depending on the treatment they received (Table 1). The number of individuals was $8-10$ per group. A total of 144 animals were used in the experiments.

\section{Drugs}

1-Methyl-1,2,3,4-tetrahydroisoquinoline (1MeTIQ) was synthesized by the Department of Drug Chemistry, Maj Institute of Pharmacology Polish Academy of Sciences, Krakow, Poland. The purity of the compound was verified by measurement of the melting point, and homogeneity was assessed on a chromatographic column. MK-801 (Sigma-Aldrich, 
Table 1 Treatments and drug doses applied to experimental groups

\begin{tabular}{llllll}
\hline Treatment & SAL & MK-801 & Olanzapine & 1MeTIQ 1x & 1MeTIQ \\
Group & & $0.3 \mathrm{mg} / 0.1 \mathrm{mg}$ & $3 \mathrm{mg}$ & $25 \mathrm{mg}$ & $7 \mathrm{x} 25 \mathrm{mg}$ \\
\hline Control & + & & & \\
MK-801 & + & + & + & + \\
Olanzapine & + & & & + \\
1MeTIQ-1x & + & & + & + \\
1MeTIQ-7x & + & & & + \\
Olanzapine + MK-801 & & + & & + \\
1MeTIQ-1x + MK-801 & & + & & \\
1MeTIQ-7x + MK-801 & & + & & \\
\hline
\end{tabular}

+ refers to administration of a particular drug. Animals were divided into 8 groups, including the control (saline) group. $N=8-10$. The doses of MK-801 were different for FM $(0.3 \mathrm{mg} / \mathrm{kg}$, ip) and the SIT $(0.1 \mathrm{mg} /$ $\mathrm{kg}, s c)$
USA) and $1 \mathrm{MeTIQ}$ were dissolved in sterile $0.9 \% \mathrm{NaCl}$ solution and injected in a volume of $1 \mathrm{ml} / \mathrm{kg}$. Olanzapine (Sigma-Aldrich, USA) was suspended in a $1 \%$ aqueous solution of Tween 80.

\section{Biochemical analysis of monoamines and their metabolites}

Immediately after the behavioral test, rats were decapitated. The Fcx and hippocampus were dissected and frozen on solid $\mathrm{CO}_{2}\left(-70^{\circ} \mathrm{C}\right)$ and stored until biochemical assays. Dopamine (DA) along with its metabolites 3,4-dihydroxyphenylacetic acid (DOPAC), 3-methoxytyramine (3-MT) and homovanillic acid (HVA, the final metabolite); seroto$\operatorname{nin}(5-\mathrm{HT})$ along with its metabolite 5-hydroxyindoleacetic acid (5-HIAA); and noradrenaline (NA) along with its metabolite normetanephrine (NM) were assayed by means of high-performance liquid chromatography (HPLC) with electrochemical detection. The chromatograph (HP 1050; Hewlett-Packard, Golden, CO, USA) was equipped with C18 columns. The sample preparation procedure was based on our previous protocol [24].

\section{Fear conditioning}

Fear conditioning (FC) and memory tests were performed and analyzed using a computer-controlled FC system (TSE, Bad Homburg, Germany), as previously described by Chocyk et al. [3]. Each FC unit consisted of sound-attenuating housing with a loudspeaker, camera, ventilation fan and four symmetrically mounted lamps in the ceiling construction and test box.

During the experimental procedure, the animals were tested in two different arenas and contexts (A and B). For the first context (Context A), the arena $(46 \times 46 \times 47 \mathrm{~cm})$ was made of transparent acrylic and had a floor made up of stainless steel rods (4 $\mathrm{mm}$ in diameter) spaced $8.9 \mathrm{~mm}$ apart (center to center). The floor was connected to a shocker-scrambler unit for delivering shocks of defined duration and intensity. The test arena was cleaned with $1 \%$ acetic acid solution. A ventilation fan provided background noise $(65 \mathrm{~dB})$, and lamps provided uniform illumination of $60 \mathrm{~lx}$ inside the FC housing. During tests in Context A, the room lights remained on. Animals were transported to this context with transparent plastic boxes. Experimenters wore white clothes and gloves.

For the second context (Context B), the arena $(46 \times 46 \times 47 \mathrm{~cm})$ was made of black acrylic with a gray plastic floor. The arena was cleaned with $70 \%$ ethanol solution and faintly illuminated (4 lx). The tests in Context B were conducted with the room light off. Animals were transported to this context with black plastic boxes. Experimenters wore blue clothes and gloves. All sessions were recorded and archived for further verification.

FC and memory were assessed using the Pavlovian paradigm. On day 1 of the experiment, all animals were subjected to FC in Context A (acquisition/training). 1 MeTIQ (25 mg/kg, ip) or olanzapine (3 mg/kg, ip) was given 35 min before training, whereas MK-801 $(0.3 \mathrm{mg} /$ $\mathrm{kg}$, ip) was administered once, 15 min before training. In the chronic treatment groups, the last dose of $1 \mathrm{MeTIQ}$ was given $35 \mathrm{~min}$ before training. Animals were placed in context A and allowed to habituate for $180 \mathrm{~s}$. Next, the animals received five tone-shock pairings in which the tone (amplitude: $80 \mathrm{~dB}$; frequency: $2 \mathrm{kHz}$; duration: $10 \mathrm{~s})$ coterminated with foot shock (intensity: $1 \mathrm{~mA}$; duration: $1 \mathrm{~s}$ ). The intertrial interval was $60 \mathrm{~s}$. Animals were removed from context A $60 \mathrm{~s}$ after the last trial.

On day 2, all animals were once again exposed to Context $\mathrm{A}$ and were left undisturbed for 6 min (expression of contextual fear conditioning, $\mathrm{CFC}$ ) and then returned to their home cages. Two hours later, animals were placed in a new context (Context B) and, after $180 \mathrm{~s}$ of habituation, received five presentations of tone alone with $61 \mathrm{~s}$ 
intertrial intervals (expression of auditory fear conditioning, AFC).

Behavioral responses during all sessions were recorded and automatically analyzed using FC software (TSE, Bad Homburg, Germany). Freezing (i.e., immobility) was taken as the behavioral measure of fear and was defined as the absence of all nonrespiratory movements for at least $2 \mathrm{~s}$. The cumulative duration of freezing was calculated for each session and expressed as a percentage of the entire session time, excluding habituation time, in the case of AFC expression (Fig. 1).

\section{Social interaction test}

The SIT was performed using a black wooden box $(60 \times 60 \times 25 \mathrm{~cm})$. The arena was dimly illuminated with indirect light of 18 lx. Each social interaction experiment involving two rats was carried out during the light phase of the light/dark cycle. The rats were selected from separate housing cages to make a pair for the study. The paired rats were matched for body weight within $15 \mathrm{~g}$. Each trial involved two same-treated rats. MK-801 $(0.1 \mathrm{mg} / \mathrm{kg}, s c)$ was administered once, $240 \mathrm{~min}$ before SIT. In the combined groups 1MeTIQ ( $25 \mathrm{mg} / \mathrm{kg}$, ip ) or olanzapine ( $3 \mathrm{mg}$ / $\mathrm{kg}, i p$ ) was given $210 \mathrm{~min}$ after MK-801 injections. In the chronic treatment groups, the last dose of 1 MeTIQ was given 30 min before SIT (Fig. 2).

Each pair of rats was diagonally placed in opposite corners of the box. The behavior of animals was measured over a 10-min period. The test box was wiped clean between each trial. Social interaction between two rats was expressed as the total time spent in social behavior, such as sniffing, genital investigation, chasing and fighting with each other. The number of episodes was counted as a separate paradigm. Each group consisted of 12 animals (6 pairs) [30].

\section{Statistical analysis}

The results of behavioral tests and biochemical analysis (acute treatment) were analyzed by means of one-way ANOVA followed, when appropriate, by a post hoc Duncan's multiple range test (MRT). The results from behavioral tests and biochemical analysis of chronic treatment were analyzed by means of two-way ANOVA followed, when appropriate, by a post hoc Duncan's MRT. The results were considered statistically significant when $p<0.05$.

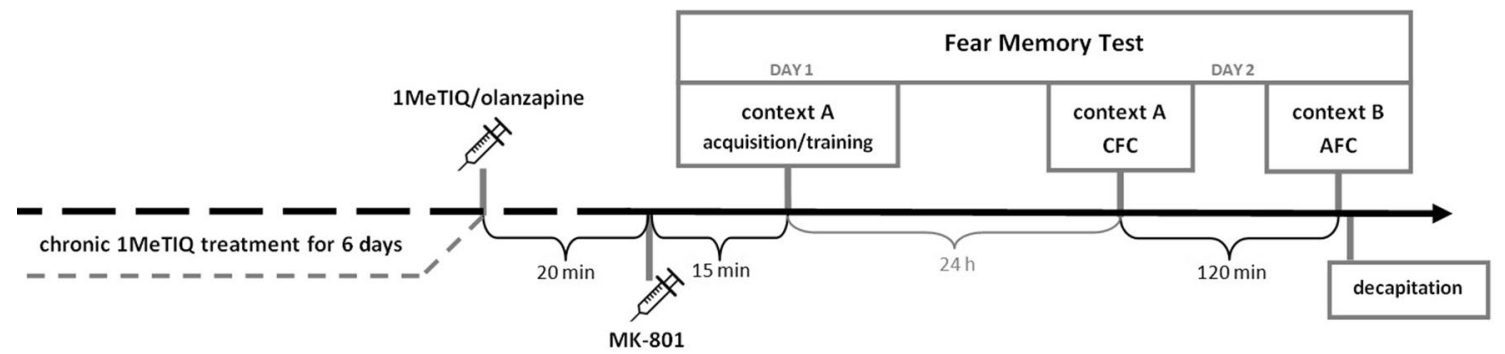

Fig. 1 Schematic representation of the FM experiment. Chronic treatment with 1MeTIQ lasted for 7 days, and the last dose was given on the day of the experiment 20 min before MK-801. The FM test consisted of the acquisition/training phase in Context A (day 1) and the testing phase in Context $\mathrm{A}-\mathrm{CFC}$ and Context $\mathrm{B}-\mathrm{AFC}$ (day 2). The interval between $\mathrm{CFC}$ and $\mathrm{AFC}$ on day 2 lasted $2 \mathrm{~h} . N=8-10$ rats per group. After behavioral testing, animals were immediately decapitated

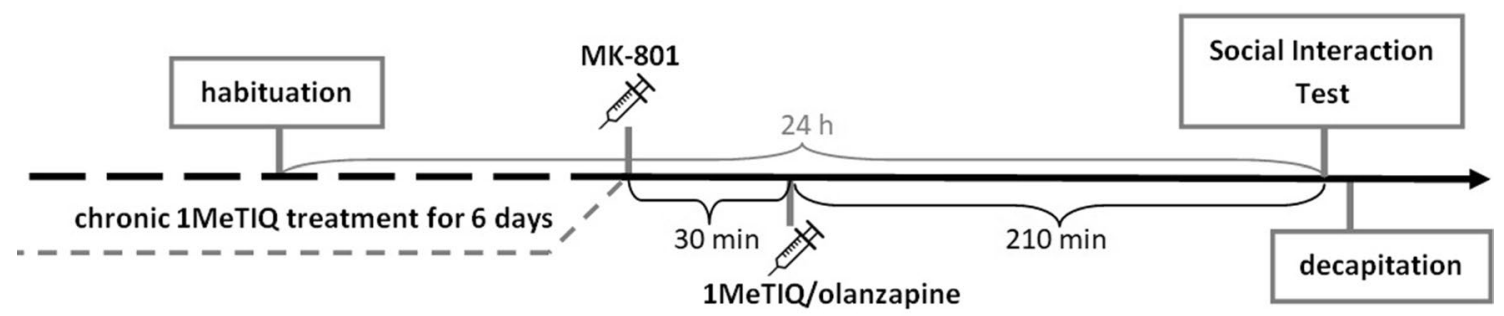

Fig. 2 Schematic representation of the SIT. Chronic treatment with 1MeTIQ lasted for 7 days, and the last dose was given on the day of the experiment $30 \mathrm{~min}$ after MK-801 and $210 \mathrm{~min}$ before behavioral testing. The SIT consisted of habituation and general testing with a 24-h intervening interval. $N=8-10$ rats per group. Immediately after the test, animals were decapitated 


\section{Results}

\section{Frontal cortex-biochemical analysis; acute 1 MeTIQ treatment}

\section{Dopamine and its metabolites}

One-way ANOVA revealed a significant $\left(F_{5,36}=11.31\right.$, $p<0.001)$ effect of the applied treatment on DA levels in the Fcx of rats. Post hoc tests showed a significantly decreased DA level in animals treated with MK-801 compared to saline $(p<0.001)$, and this effect was reversed by an acute dose of either 1MeTIQ or olanzapine. In both combined groups, the DA concentration returned to the control level (Table 2).

One-way ANOVA showed a significant $\left(F_{5,38}=37.92\right.$, $p<0.001)$ effect of the treatment on frontal DOPAC levels. Duncan's MRT showed a decreased DOPAC level after treatment with both 1MeTIQ and MK-801 (compared to saline or MK-801; both $p<0.05$ ). We observed an increased DOPAC level after olanzapine was given either alone (compared to saline; $p<0.001$ ) or combined with MK-801 (compared to the saline and MK-801 groups; both $p<0.001$ ) (Table 2).

One-way ANOVA revealed no significant difference $\left(F_{5,39}=0.97, p=0.45\right)$ effect of the treatment on the 3-MT level (Table 2).
The same analysis showed a significant $\left(F_{5,39}=12.72\right.$, $p<0.001)$ effect of the treatment on HVA levels in the Fcx. Post hoc analysis showed a significantly increased level of HVA after olanzapine treatment compared to saline $(p<0.001)$. Olanzapine given with MK-801 increased the HVA level compared to both saline $(p<0.01)$ and MK-801 $(p<0.001)$ (Table 2).

\section{Noradrenaline and normetanephrine (NM)}

One-way ANOVA showed a significant $\left(F_{5,39}=4.38\right.$, $p<0.01)$ effect of the applied treatment on NA levels. Post hoc tests revealed that treatment with MK-801, 1MeTIQ or olanzapine alone caused a significant increase in the level of HVA compared to the control $(p<0.05 ; p<0.001 ; p<0.01$, respectively). A similar effect was observed in groups with $1 \mathrm{MeTIQ}$ or olanzapine given in conjunction with MK-801 ( $p<0.001$ and $p<0.01$, respectively) (Table 3 ).

One-way ANOVA revealed a significant $\left(F_{5,37}=12.65\right.$, $p<0.001$ ) effect of the treatment on NM levels. 1MeTIQ caused a significant increase in the level of NM compared to the control $(p<0.001)$. 1MeTIQ given together with MK-801 increased the NM level significantly compared to those of the saline and MK-801 groups $(p<0.001)$ (Table 3).
Table 2 Results from the biochemical assay after acute 1 MeTIQ treatment

\begin{tabular}{|c|c|c|c|c|c|}
\hline Treatment & $n$ & DA & DOPAC & 3-MT & HVA \\
\hline \multicolumn{6}{|l|}{ FCX } \\
\hline Control & 5 & $510 \pm 29$ & $159 \pm 7$ & $14 \pm 1$ & $155 \pm 14$ \\
\hline MK-801 & 5 & $213 \pm 36 * * *$ & $158 \pm 10$ & $17 \pm 2$ & $121 \pm 16$ \\
\hline 1MeTIQ & 8 & $458 \pm 39$ & $96 \pm 6$ & $27 \pm 5$ & $152 \pm 7$ \\
\hline Olanzapine & 10 & $319 \pm 26^{* *}$ & $326 \pm 14 * * *$ & $30 \pm 11$ & $272 \pm 20 * * *$ \\
\hline 1MeTIQ+MK-801 & 5 & $490 \pm 46^{\# \# \#}$ & $92 \pm 8^{* \#}$ & $24 \pm 4$ & $127 \pm 6$ \\
\hline Olanzapine + MK-801 & 9 & $543 \pm 37^{\# \# \#}$ & 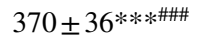 & $19 \pm 2$ & 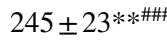 \\
\hline$F$ & & $\begin{array}{l}\mathrm{F}_{(5 / 36)}=11.31 \\
\mathrm{p}<0.001\end{array}$ & $\begin{array}{l}\mathrm{F}_{(5 / 38)}=37.92 \\
\mathrm{p}<0.001\end{array}$ & $\begin{array}{l}\mathrm{F}_{(5 / 39)}=0.97 \\
\mathrm{p}=0.45\end{array}$ & $\begin{array}{l}\mathrm{F}_{(5 / 39)}=12.72 \\
\mathrm{p}<0.001\end{array}$ \\
\hline \multicolumn{6}{|l|}{ HIP } \\
\hline Control & 5 & $25 \pm 1$ & $11 \pm 1$ & $15 \pm 2$ & $17 \pm 2$ \\
\hline MK-801 & 6 & $23 \pm 3$ & $17 \pm 1^{*}$ & $13 \pm 1$ & $21 \pm 3$ \\
\hline 1MeTIQ & 10 & $34 \pm 2 *$ & $12 \pm 1$ & $20 \pm 3$ & $26 \pm 3$ \\
\hline Olanzapine & 9 & $31 \pm 2$ & $26 \pm 2 * * *$ & $22 \pm 3^{*}$ & $26 \pm 3$ \\
\hline 1MeTIQ+MK-801 & 6 & $29 \pm 2$ & $12 \pm 1^{+}$ & $10 \pm 1$ & $19 \pm 3$ \\
\hline Olanzapine + MK-801 & 10 & $22 \pm 2$ & $17 \pm 2 *$ & $11 \pm 1$ & $26 \pm 3$ \\
\hline$F$ & & $\begin{array}{l}\mathrm{F}_{(5 / 40)}=4.38 \\
\mathrm{p}<0.01\end{array}$ & $\begin{array}{l}\mathrm{F}_{(5 / 39)}=15.42 \\
\mathrm{p}<0.001\end{array}$ & $\begin{array}{l}\mathrm{F}_{(5 / 38)}=4.36 \\
\mathrm{p}<0.01\end{array}$ & $\begin{array}{l}\mathrm{F}_{(5 / 38)}=1.51 \\
\mathrm{p}=0.21\end{array}$ \\
\hline
\end{tabular}

DA and its metabolites were measured in the Fcx and hippocampus using HPLC. The data were analyzed using one-way ANOVA and a post hoc Duncan's MRT. The results are shown as the means \pm SEM. $N=8-10$ rats per group

${ }^{*} p<0.05 ; * * p<0.01 ; * * * p<0.001$ indicate significant changes compared to the control; ${ }^{*} p<0.05$; ${ }^{\# \#} p<0.01 ;{ }^{\# \#} p<0.001$ indicate significant changes compared to the model (MK-801) group 
Table 3 Results from the biochemical assay after acute 1MeTIQ treatment

\begin{tabular}{|c|c|c|c|c|c|}
\hline Treatment & $n$ & NA & NM & $5-\mathrm{HT}$ & 5-HIAA \\
\hline \multicolumn{6}{|l|}{ FCX } \\
\hline Control & 5 & $265 \pm 15$ & $17 \pm 3$ & $253 \pm 12$ & $243 \pm 5$ \\
\hline MK-801 & 5 & $307 \pm 22^{*}$ & $26 \pm 3$ & $250 \pm 18$ & $241 \pm 11$ \\
\hline 1MeTIQ & 9 & $336 \pm 11 * * *$ & $44 \pm 4 * * *$ & $343 \pm 11 * * *$ & $202 \pm 9 * *$ \\
\hline Olanzapine & 10 & $316 \pm 7 * *$ & $20 \pm 3$ & $262 \pm 9$ & $254 \pm 11$ \\
\hline 1MeTIQ+MK-801 & 6 & $341 \pm 10 * * *$ & $48 \pm 7 * * * \# \# \#$ & $333 \pm 14 * * * \# \#$ & $171 \pm 11 * * * \# \#$ \\
\hline Olanzapine + MK-801 & 10 & $319 \pm 9 * *$ & $22 \pm 2$ & $252 \pm 9$ & $244 \pm 7$ \\
\hline$F$ & & $\begin{array}{l}\mathrm{F}_{(5 / 39)}=4.38 \\
\mathrm{p}<0.01\end{array}$ & $\begin{array}{l}\mathrm{F}_{(5 / 37)}=12.65 \\
\mathrm{p}<0.001\end{array}$ & $\begin{array}{l}\mathrm{F}_{(5 / 42)}=13.92 \\
\mathrm{p}<0.001\end{array}$ & $\begin{array}{l}\mathrm{F}_{(5 / 41)}=10.40 \\
\mathrm{p}<0.001\end{array}$ \\
\hline \multicolumn{6}{|l|}{ HIP } \\
\hline Control & 6 & $301 \pm 20$ & $24 \pm 3$ & $226 \pm 13$ & $309 \pm 12$ \\
\hline MK-801 & 6 & $295 \pm 16$ & $25 \pm 4$ & $202 \pm 18$ & $327 \pm 16$ \\
\hline 1MeTIQ & 10 & $341 \pm 20$ & $44 \pm 4 * * *$ & $284 \pm 14 * *$ & $288 \pm 10$ \\
\hline Olanzapine & 9 & $289 \pm 10$ & $33 \pm 3$ & $235 \pm 10$ & $356 \pm 9$ \\
\hline 1MeTIQ+ MK-801 & 6 & $295 \pm 14$ & $32 \pm 3$ & $265 \pm 10^{* \# \#}$ & $255 \pm 22^{\#}$ \\
\hline Olanzapine + MK-801 & 9 & $313 \pm 21$ & $22 \pm 1$ & $217 \pm 8$ & $302 \pm 23$ \\
\hline$F$ & & $\begin{array}{l}\mathrm{F}_{(5 / 40)}=1.35 \\
\mathrm{p}=0.26\end{array}$ & $\begin{array}{l}\mathrm{F}_{(5 / 39)}=7.07 \\
\mathrm{p}<0.001\end{array}$ & $\begin{array}{l}\mathrm{F}_{(5 / 40)}=6.33 \\
\mathrm{p}<0.001\end{array}$ & $\begin{array}{l}\mathrm{F}_{(5 / 40)}=3.91 \\
\mathrm{p}<0.01\end{array}$ \\
\hline
\end{tabular}

NA, 5-HT and their metabolites (NM, 5-HIAA) were measured in the Fcx and hippocampus using HPLC. The data were analyzed using one-way ANOVA and a post hoc Duncan's MRT. The results are shown as the means \pm SEM. $N=8-10$ rats per group

$* p<0.05 ; * * p<0.01 ; * * * p<0.001$ indicate significant changes compared to the control; ${ }^{*} p<0.05$; ${ }^{\# \#} p<0.01 ; \#$;\# $<0.001$ indicate significant changes compared to the model (MK-801) group

\section{Serotonin and 5-hydroxyindoleacetic acid (5-HIAA)}

One-way ANOVA showed a significant $\left(F_{5,42}=13.92\right.$, $p<0.001)$ effect of the treatment on frontal 5-HT levels. Post hoc tests showed a significant increase in 5-HT after 1MeTIQ ( $p<0.001$, compared to saline) and 1MeTIQ given with MK-801 (compared to saline or MK-801; both $p<0.001$ ) (Table 3).

One-way ANOVA revealed a significant $\left(F_{5,41}=10.40\right.$, $p<0.001)$ effect of the applied treatment on the 5-HIAA level. Duncan's MRT showed a decreased 5-HIAA level after 1MeTIQ given alone (compared to saline; $p<0.01$ ) and 1MeTIQ given with MK-801 (compared to saline or MK-801; both $p<0.001$ ) (Table 3).

\section{Hippocampus-biochemical analysis; acute 1 MeTIQ treatment}

\section{Dopamine and its metabolites}

One-way ANOVA showed a significant $\left(F_{5,40}=4.38\right.$, $p<0.01)$ effect of the treatment on DA levels in the hippocampus. Post hoc analysis showed a significantly higher DA level after 1MeTIQ $(p<0.05)$ compared to saline (Table 2).

The statistical analysis showed a significant $\left(F_{5,39}=15.42\right.$, $p<0.001)$ effect of the treatment on DOPAC levels. Post hoc tests showed significantly higher amounts of DOPAC after MK-801 or olanzapine treatment compared to the control ( $p<0.05 ; p<0.001$, respectively). A similar effect was observed in the combined group treated with olanzapine and MK-801 $(p<0.05)$ (Table 2).

One-way ANOVA revealed a significant $\left(F_{5,38}=4.36\right.$, $p<0.01$ ) effect of the treatment on the 3-MT level. Post hoc tests showed that olanzapine given alone caused a significant increase in 3-MT compared to saline $(p<0.05)$ (Table 2).

The same analysis showed no significant $\left(F_{5,38}=1.51\right.$, $p=0.21$ ) effect of the treatment on the HVA level (Table 2).

\section{Noradrenaline and normetanephrine}

One-way ANOVA revealed no significant $\left(F_{5,40}=1.35\right.$, $p=0.26$ ) effect of the treatment on the NA level in the hippocampus.

The same analysis showed a significant $\left(F_{5,39}=7.07\right.$, $p<0.001)$ effect of the treatment on NM levels. Post hoc tests showed significantly increased NM levels after 1MeTIQ administration compared to the control $(p<0.001)$ (Table 3$)$.

\section{Serotonin and 5-hydroxyindoleacetic acid}

One-way ANOVA showed a significant $\left(F_{5,40}=6.33\right.$, $p<0.001)$ effect of the treatment on 5-HT levels in the hippocampus. Duncan's MRT revealed significantly increased 
5-HT amounts after 1MeTIQ (compared to saline: $p<0.01$ ) and 1MeTIQ combined with MK-801 (compared to saline: $p<0.05$; MK-801: $p<0.01$ ) (Table 3).

The statistical analysis showed a significant $\left(F_{5,40}=3.91\right.$, $p<0.01)$ effect of the treatment on the 5-HIAA level. Post hoc tests showed that $1 \mathrm{MeTIQ}$ given with MK-801 caused a significant decrease in 5-HIAA compared to MK-801-treated animals $(p<0.05)$ (Table 3$)$.

\section{Frontal cortex-biochemical analysis; chronic 1 MeTIQ treatment}

\section{Dopamine and its metabolites}

Two-way ANOVA revealed no significant $\left(F_{1,18}=1.28\right.$, $p=0.27$ ) effect of MK-801 on frontal DA level. The same analysis showed a significant effect of chronic 1 MeTIQ $\left(F_{1,18}=9.91, p<0.01\right)$ and the interaction of both treatments $\left(F_{1,18}=21.10, p<0.001\right)$ on DA levels. Post hoc tests revealed significantly decreased levels of DA after MK-801 treatment compared to the control $(p<0.01)$. In the combined group, chronic 1MeTIQ reversed the effect of MK-801 and increased DA levels to the control level $(p<0.001)$ (Table 4).
Two-way ANOVA revealed a nonsignificant $\left(F_{1,19}=0.58, p=0.45\right)$ effect of MK-801 and a significant $\left(F_{1,19}=71.72, p<0.001\right)$ effect of chronic 1MeTIQ on DOPAC levels. The effect of the interaction of both treatments was found to be nonsignificant $\left(F_{1,19}=0.73\right.$, $p=0.40)$. Duncan's MRT showed decreased DOPAC levels after chronic 1MeTIQ treatment compared to the control $(p<0.001)$. A similar effect was observed in animals treated with both 1MeTIQ and MK-801 (compared to saline or MK-801: both $p<0.001$ ) (Table 4 ).

Two-way ANOVA showed a nonsignificant $\left(F_{1,21}=0.29\right.$, $p=0.59)$ effect of MK-801 and a significant $\left(F_{1,21}=12.50\right.$, $p<0.01)$ effect of chronic 1MeTIQ on the 3-MT level. The interaction of both treatments was found to be nonsignificant $\left(F_{1,21}=1.48, p=0.24\right)$. Post hoc tests showed increased 3-MT levels after chronic 1MeTIQ administration compared to the control $(p<0.01)$ (Table 4).

Two-way ANOVA showed no significant effect of MK-801 $\left(F_{1,22}=1.90, p=0.18\right)$, chronic 1MeTIQ $\left(F_{1,22}=0.96, p=0.34\right)$ or the interaction of both treatments $\left(F_{1,22}=2.48, p=0.13\right)$ on the HVA level in the frontal cortex (Table 4).
Table 4 Results from the biochemical assay after chronic (7x) 1MeTIQ treatment

\begin{tabular}{|c|c|c|c|c|c|}
\hline Treatment & $n$ & DA & DOPAC & 3-MT & HVA \\
\hline \multicolumn{6}{|l|}{ FCX } \\
\hline Control & 5 & $510 \pm 29$ & $159 \pm 7$ & $14 \pm 1$ & $155 \pm 14$ \\
\hline MK-801 & 7 & $213 \pm 36 * *$ & $158 \pm 10$ & $17 \pm 2$ & $121 \pm 16$ \\
\hline 1MeTIQ-7x & 5 & $435 \pm 61$ & $81 \pm 7 * * *$ & $36 \pm 6 * *$ & $126 \pm 8$ \\
\hline 1MeTIQ-7x + MK-801 & 5 & $614 \pm 54^{\# \# \#}$ & 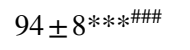 & $28 \pm 4$ & $128 \pm 7$ \\
\hline $\begin{array}{l}\text { Effect of } \mathrm{T} 1 \\
\text { Effect of } \mathrm{T} 2 \\
\text { Interaction of } \mathrm{T} 1+\mathrm{T} 2\end{array}$ & & $\begin{array}{l}\mathrm{F}_{(1 / 18)}=1.28 \\
\mathrm{p}=0.27 \\
\mathrm{~F}_{(1 / 18)}=9.91 \\
\mathrm{p}<0.01 \\
\mathrm{~F}_{(1 / 18)}=21.10 \\
\mathrm{p}<0.001\end{array}$ & $\begin{array}{l}\mathrm{F}_{(1 / 19)}=0.58 \\
\mathrm{p}=0.45 \\
\mathrm{~F}_{(1 / 19)}=71.72 \\
\mathrm{p}<0.0011 \\
\mathrm{~F}_{(1 / 19)}=0.73 \\
\mathrm{p}=0.40\end{array}$ & $\begin{array}{l}\mathrm{F}_{(1 / 21)}=0.29 \\
\mathrm{p}=0.59 \\
\mathrm{~F}_{(1 / 21)}=12.50 \\
\mathrm{p}<0.001 \\
\mathrm{~F}_{(1 / 21)}=1.48 \\
\mathrm{p}=0.24\end{array}$ & $\begin{array}{l}\mathrm{F}_{(1 / 22)}=1.90 \\
\mathrm{p}=0.18 \\
\mathrm{~F}_{(1 / 22)}=0.96 \\
\mathrm{p}=0.34 \\
\mathrm{~F}_{(1 / 22)}=2.48 \\
\mathrm{p}=0.13\end{array}$ \\
\hline \multicolumn{6}{|l|}{ HIP } \\
\hline Control & 5 & $25 \pm 1$ & $11 \pm 1$ & $15 \pm 2$ & $17 \pm 2$ \\
\hline MK-801 & 8 & $23 \pm 3$ & $17 \pm 1^{*}$ & $13 \pm 1$ & $21 \pm 3$ \\
\hline 1MeTIQ-7x & 6 & $34 \pm 2$ & $10 \pm 1$ & $18 \pm 2$ & $29 \pm 2 * *$ \\
\hline 1MeTIQ-7x + MK-801 & 4 & $35 \pm 7^{\#}$ & $10 \pm 3^{\#}$ & $15 \pm 2$ & $21 \pm 1$ \\
\hline $\begin{array}{l}\text { Effect of T1 } \\
\text { Effect of T2 }\end{array}$ & & $\begin{array}{l}\mathrm{F}_{(1 / 19)}=0.01 \\
\mathrm{p}=0.92\end{array}$ & $\begin{array}{l}\mathrm{F}_{(1 / 21)}=3.22 \\
\mathrm{p}=0.09\end{array}$ & $\begin{array}{l}\mathrm{F}_{(1 / 22)}=1.15 \\
\mathrm{p}=0.30\end{array}$ & $\begin{array}{l}\mathrm{F}_{(1 / 21)}=0.90 \\
\mathrm{p}=0.35\end{array}$ \\
\hline Interaction of $\mathrm{T} 1+\mathrm{T} 2$ & & $\begin{array}{l}\mathrm{F}_{(1 / 19)}=9.18 \\
\mathrm{p}<0.01 \\
\mathrm{~F}_{(1 / 19)}=0.73 \\
\mathrm{p}=0.73\end{array}$ & $\begin{array}{l}\mathrm{F}_{(1 / 21)}=4.68 \\
\mathrm{p}<0.05 \\
\mathrm{~F}_{(1 / 21)}=3.27 \\
\mathrm{p}=0.09\end{array}$ & $\begin{array}{l}\mathrm{F}_{(1 / 22)}=2.02 \\
\mathrm{p}=0.17 \\
\mathrm{~F}_{(1 / 22)}=0.19 \\
\mathrm{p}=0.67\end{array}$ & $\begin{array}{l}\mathrm{F}_{(1 / 21)}=5.94 \\
\mathrm{p}<0.05 \\
\mathrm{~F}_{(1 / 21)}=5.53 \\
\mathrm{p}<0.05\end{array}$ \\
\hline
\end{tabular}

DA and its metabolites (DOPAC. 3-MT. HVA) were measured in the Fcx and hippocampus using HPLC. The data were analyzed using two-way ANOVA and a post hoc Duncan's MRT. The results are shown as the means \pm SEM. $N=8-10$ rats per group

${ }^{*} p<0.05 ; * * p<0.01 ; * * * p<0.001$ indicate significant changes compared to the control; ${ }^{*} p<0.05$; $\#$ \# $p<0.01 ;{ }^{\# \#} p<0.001$ indicate significant changes compared to the model (MK-801) group 


\section{Noradrenaline and normetanephrine}

Two-way ANOVA showed a nonsignificant $\left(F_{1,21}=0.65\right.$, $p=0.43)$ effect of MK-801 and a significant $\left(F_{1,21}=18.44\right.$, $p<0.001)$ effect of chronic 1MeTIQ on NA levels. Twoway ANOVA showed a nonsignificant $\left(F_{1,21}=2.52, p=0.13\right)$ effect of the interaction of both treatments on NA levels in the Fcx. Duncan's MRT revealed increased NA levels after chronic 1MeTIQ, given either alone or with MK-801, compared to saline $(p<0.001$ and $p<0.01$, respectively) (Table 5).

Two-way ANOVA showed a nonsignificant $\left(F_{1,22}=0.21\right.$, $p=0.65$ ) effect of MK-801 on NM level. The same analysis showed a significant effect of chronic 1MeTIQ $\left(F_{1,22}=83.58, p<0.001\right)$ and the interaction of both treatments $\left(F_{1,22}=11.17, p<0.01\right)$ on NM amount. Post hoc tests revealed significantly increased levels of NM in the chronic 1MeTIQ group compared to the saline group $(p<0.001)$. A similar effect was observed in the combined group compared to the control and MK-801 animals (both $p<0.001$ ) (Table 5).

\section{Serotonin and 5-hydroxyindoleacetic acid}

Two-way ANOVA revealed a nonsignificant $\left(F_{1,23}=0.11\right.$, $p=0.75)$ effect of MK-801 and a significant $\left(F_{1,23}=38.21\right.$, $p<0.001$ ) effect of chronic 1MeTIQ on the 5-HT amount. The interaction of both treatments was found to have a nonsignificant $\left(F_{1,23}=0.03, p=0.85\right)$ effect on 5-HT level. Post hoc tests showed a significant increase in 5-HT after chronic 1MeTIQ, given either alone or with MK-801, compared to the 5-HT levels of control and MK-801 animals (all $p<0.001$ ) (Table 5).

Two-way ANOVA revealed a nonsignificant $\left(F_{1,22}=0.22, p=0.64\right)$ effect of MK-801 and a significant $\left(F_{1,22}=43.59, p<0.001\right)$ effect of chronic 1MeTIQ on 5-HIAA levels. The same analysis showed a nonsignificant $\left(F_{1,22}=0.58, p=0.45\right)$ effect of interaction of both treatments. Post hoc tests revealed depletion of 5-HIAA in the chronic 1MeTIQ group compared to the saline group $(p<0.001)$. A similar effect was observed in the combined group compared to the saline $(p<0.001)$ and MK-801 groups $(p<0.001)$ (Table 5).
Table 5 Results from the biochemical assay after chronic (7x) 1MeTIQ treatment

\begin{tabular}{|c|c|c|c|c|c|}
\hline Treatment & $n$ & NA & $\mathrm{NM}$ & 5-HT & 5-HIAA \\
\hline \multicolumn{6}{|l|}{ FCX } \\
\hline Control & 5 & $265 \pm 15$ & $17 \pm 3$ & $253 \pm 12$ & $243 \pm 8$ \\
\hline MK-801 & 9 & $307 \pm 22$ & $26 \pm 3$ & $250 \pm 18$ & $241 \pm 8$ \\
\hline 1MeTIQ-7x & 5 & $368 \pm 16^{* * *}$ & $53 \pm 3 * * *$ & $358 \pm 17 * * *$ & $187 \pm 6^{* * *}$ \\
\hline 1MeTIQ-7x + MK-801 & 6 & $354 \pm 13^{* *}$ & $42 \pm 3 * * * \# \#$ & 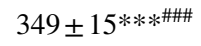 & $196 \pm 8 * * * \# \#$ \\
\hline $\begin{array}{l}\text { Effect of } \mathrm{T} 1 \\
\text { Effect of } \mathrm{T} 2 \\
\text { Interaction of } \mathrm{T} 1+\mathrm{T} 2\end{array}$ & & $\begin{array}{l}\mathrm{F}_{(1 / 21)}=0.65 \\
\mathrm{p}=0.43 \\
\mathrm{~F}_{(1 / 21)}=18.44 \\
\mathrm{p}<0.001 \\
\mathrm{~F}_{(1 / 21)}=2.52 \\
\mathrm{p}=0.13\end{array}$ & $\begin{array}{l}\mathrm{F}_{(1 / 22)}=0.21 \\
\mathrm{p}=0.65 \\
\mathrm{~F}_{(1 / 22)}=83.58 \\
\mathrm{p}<0.001 \\
\mathrm{~F}_{(1 / 22)}=11.17 \\
\mathrm{p}<0.01\end{array}$ & $\begin{array}{l}\mathrm{F}_{(1 / 23)}=0.11 \\
\mathrm{p}=0.75 \\
\mathrm{~F}_{(1 / 23)}=38.21 \\
\mathrm{p}<0.001 \\
\mathrm{~F}_{(1 / 23)}=0.03 \\
\mathrm{p}=0.85\end{array}$ & $\begin{array}{l}\mathrm{F}_{(1 / 22)}=0.22 \\
\mathrm{p}=0.64 \\
\mathrm{~F}_{(1 / 22)}=43.59 \\
\mathrm{p}<0.001 \\
\mathrm{~F}_{(1 / 22)}=0.58 \\
\mathrm{p}=0.45\end{array}$ \\
\hline \multicolumn{6}{|l|}{ HIP } \\
\hline Control & 6 & $301 \pm 20$ & $24 \pm 3$ & $226 \pm 13$ & $309 \pm 12$ \\
\hline MK-801 & 9 & $295 \pm 16$ & $25 \pm 4$ & $202 \pm 18$ & $327 \pm 16$ \\
\hline 1MeTIQ-7x & 6 & $356 \pm 16^{*}$ & $44 \pm 3 * *$ & $337 \pm 26^{* *}$ & $273 \pm 9$ \\
\hline 1MeTIQ-7x + MK-801 & 6 & $369 \pm 18^{* \#}$ & $41 \pm 4^{* * \# \#}$ & $317 \pm 21^{* * \# \#}$ & $299 \pm 32$ \\
\hline $\begin{array}{l}\text { Effect of } \mathrm{T} 1 \\
\text { Effect of } \mathrm{T} 2 \\
\text { Interaction of } \mathrm{T} 1+\mathrm{T} 2\end{array}$ & & $\begin{array}{l}\mathrm{F}_{(1 / 23)}=0.03 \\
\mathrm{p}=0.85 \\
\mathrm{~F}_{(1 / 23)}=12.13 \\
\mathrm{p}<0.01 \\
\mathrm{~F}_{(1 / 23)}=0.26 \\
\mathrm{p}=0.62\end{array}$ & $\begin{array}{l}\mathrm{F}_{(1 / 22)}=0.08 \\
\mathrm{p}=0.77 \\
\mathrm{~F}_{(1 / 22)}=21.38 \\
\mathrm{p}<0.001 \\
\mathrm{~F}_{(1 / 22)}=0.36 \\
\mathrm{p}=0.55\end{array}$ & $\begin{array}{l}\mathrm{F}_{(1 / 23)}=0.94 \\
\mathrm{p}=0.34 \\
\mathrm{~F}_{(1 / 23)}=25.25 \\
\mathrm{p}<0.001 \\
\mathrm{p}<0.01 \\
\mathrm{p}=0.93\end{array}$ & $\begin{array}{l}\mathrm{F}_{(1 / 22)}=1.40 \\
0.25 \mathrm{p}= \\
\mathrm{F}_{(1 / 22)}=2.89 \\
\mathrm{p}<0.10 \\
\mathrm{~F}_{(1 / 22)}=0.04 \\
\mathrm{p}=0.83\end{array}$ \\
\hline
\end{tabular}

NA, 5-HT and their metabolites (NM. 5-HIAA) were measured in the Fcx and hippocampus using HPLC. The data were analyzed using two-way ANOVA and a post hoc Duncan's MRT. The results are shown as the means \pm SEM. $N=8-10$ rats per group

${ }^{*} p<0.05 ; * * p<0.01 ; * * * p<0.001$ indicate significant changes compared to the control; ${ }^{*} p<0.05$; ${ }^{\#} p<0.01 ;{ }^{\# \#} p<0.001$ indicate significant changes compared to the model (MK-801) group 


\section{Hippocampus-biochemical analysis; chronic 1 MeTIQ treatment}

\section{Dopamine and its metabolites}

Two-way ANOVA revealed a nonsignificant $\left(F_{1,19}=0.01\right.$, $p=0.92)$ effect of MK-801 and a significant $\left(F_{1.19}=9.18\right.$, $p<0.01)$ effect of chronic 1MeTIQ on DA amount. The same analysis showed a nonsignificant $\left(F_{1,19}=0.73\right.$, $p=0.73$ ) effect of interaction of both treatments. Duncan's MRT revealed that chronic 1MeTIQ given together with MK-801 significantly increased DA levels compared to those of the MK-801 group $(p<0.05)$ (Table 4$)$.

The same analysis showed a nonsignificant $\left(F_{1,21}=3.22\right.$, $p=0.09)$ effect of MK-801 and a significant $\left(F_{1,21}=4.68\right.$, $p<0.05)$ effect of chronic 1MeTIQ on DOPAC amount. The two treatments had no significant interaction effect $\left(F_{1,21}=3.27, p=0.09\right)$. Post hoc tests showed a significant increase in DOPAC after MK-801 compared to the control $(p<0.05)$. Chronic 1MeTIQ given with MK-801 decreased DOPAC levels compared to MK-801 animals $(p<0.05)$ and restored DOPAC to control levels (Table 4).

Two-way ANOVA revealed a nonsignificant effect of MK-801 $\left(F_{1,22}=1.15, p=0.30\right)$, chronic 1MeTIQ $\left(F_{1,22}=2.02, p=0.17\right)$ or interaction of both treatments $\left(F_{1,22}=0.19, p=0.67\right)$ on 3-MT level (Table 4).

Statistical analysis showed a nonsignificant $\left(F_{1.21}=0.90\right.$, $p=0.35)$ effect of MK-801, a significant effect of chronic 1MeTIQ $\left(F_{1,21}=5.94, p<0.05\right)$ and a significant interaction of both treatments $\left(F_{1,21}=5.53, p<0.05\right)$ on HVA amount. Post hoc tests showed a significant increase in HVA after chronic 1MeTIQ administration compared to saline $(p<0.01)$ (Table 4).

\section{Noradrenaline and normetanephrine}

Two-way ANOVA showed a nonsignificant $\left(F_{1,23}=0.03\right.$, $p=0.85)$ effect of MK-801 and a significant $\left(F_{1,23}=12.13\right.$, $p<0.01)$ effect of chronic 1MeTIQ on NA amount. There was a nonsignificant $\left(F_{1,23}=0.26, p=0.62\right)$ effect of interaction of both treatments. Duncan's MRT showed that chronic 1MeTIQ given alone increased NA levels compared to saline $(p<0.05)$. A similar effect was observed in the combined group compared to the control or MK-801 animals (both $p<0.05$ ) (Table 5).

Two-way ANOVA showed a nonsignificant $\left(F_{1,22}=0.08, p=0.77\right)$ effect of MK-801 and a significant $\left(F_{1,22}=21.38, p<0.001\right)$ effect of chronic 1MeTIQ on NM levels. The same analysis showed a nonsignificant $\left(F_{1,22}=0.36, p=0.55\right)$ effect of interaction of both treatments. Post hoc tests revealed an increased NM amount after chronic 1MeTIQ compared to the control $(p<0.01)$. A similar effect was observed in the group treated with both chronic 1 MeTIQ and MK-801 compared to the control and MK-801 groups (both $p<0.01$ ) (Table 5).

\section{Serotonin and 5-hydroxyindoleacetic acid}

Two-way ANOVA revealed a nonsignificant effect of MK-801 $\left(F_{1,23}=0.94, p=0.34\right)$ and a nonsignificant interaction between the two treatments $\left(F_{1,23}=0.01\right.$, $p=0.93$ ) on 5-HT level. However, there was a significant $\left(F_{1,23}=25.25, p<0.001\right)$ effect of chronic 1MeTIQ on the 5-HT amount. Duncan's MRT showed that chronic 1 MeTIQ caused a significant increase in 5-HT compared to the control $(p<0.01)$. A similar effect was observed in the combined group when compared to the saline or MK-801 group (both $p<0.01$ ) (Table 5).

Two-way ANOVA showed no significant effect of MK-801 $\left(F_{1,22}=1.40, p=0.25\right)$, chronic 1MeTIQ $\left(F_{1,22}=2.89, p=0.10\right)$ and the interaction of both treatments $\left(F_{1,22}=0.04, p=0.83\right)$ on the 5-HIAA amount (Table 5).

\section{Fear conditioning}

\section{Acute treatment with $1 \mathrm{MeTIQ}$ - contextual fear conditioning (CFC)}

One-way ANOVA showed a significant effect $\left(F_{5,46}=15.50\right.$, $p<0.001$ ) of treatment on $\%$ freezing time in CFC. Post hoc tests showed a significant $(p<0.001)$ decrease in $\%$ freezing time after MK-801 treatment. Acute administration of olanzapine significantly $(p<0.01)$ decreased the $\%$ freezing time compared to the saline group. Combined treatment with both 1MeTIQ and MK-801 significantly $(p<0.001)$ reduced the $\%$ freezing time compared to that of the control group. Olanzapine given with MK-801 significantly $(p<0.001)$ decreased the $\%$ freezing time in the CFC (Fig. 3a).

\section{Acute treatment with 1MeTIQ-auditory fear conditioning (AFC)}

One-way ANOVA revealed a significant effect $\left(F_{5,45}=7.14\right.$, $p<0.001)$ of applied treatment on $\%$ freezing time in AFC. Post hoc tests showed a significant $(p<0.01)$ decrease in $\%$ freezing time after MK-801 treatment. Combined treatment with both 1MeTIQ and MK-801 significantly $(p<0.01)$ decreased the $\%$ freezing time in the AFC compared to the saline group. Olanzapine given together with MK-801 significantly $(p<0.001)$ reduced $\%$ freezing time. However, neither of the combined treatments reversed the effect of MK-801 (Fig. 3b). 


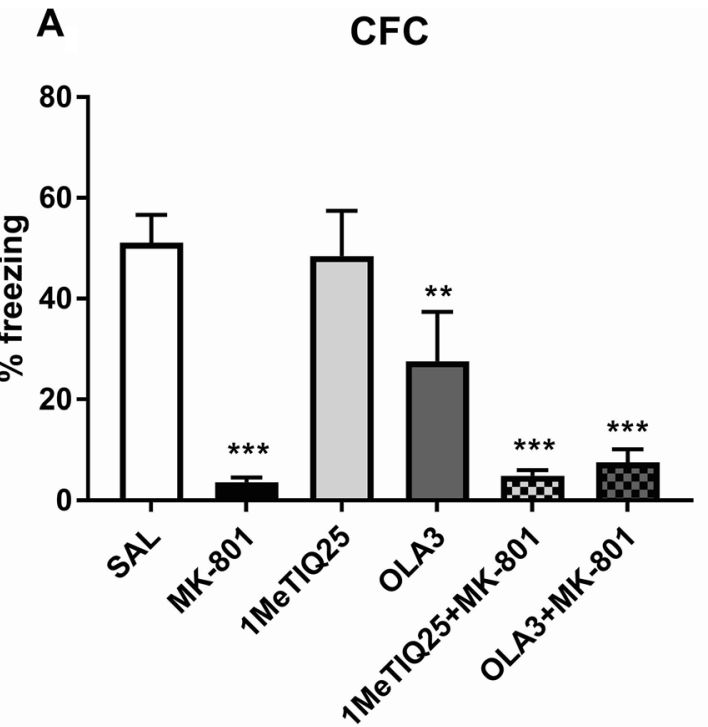

treatment

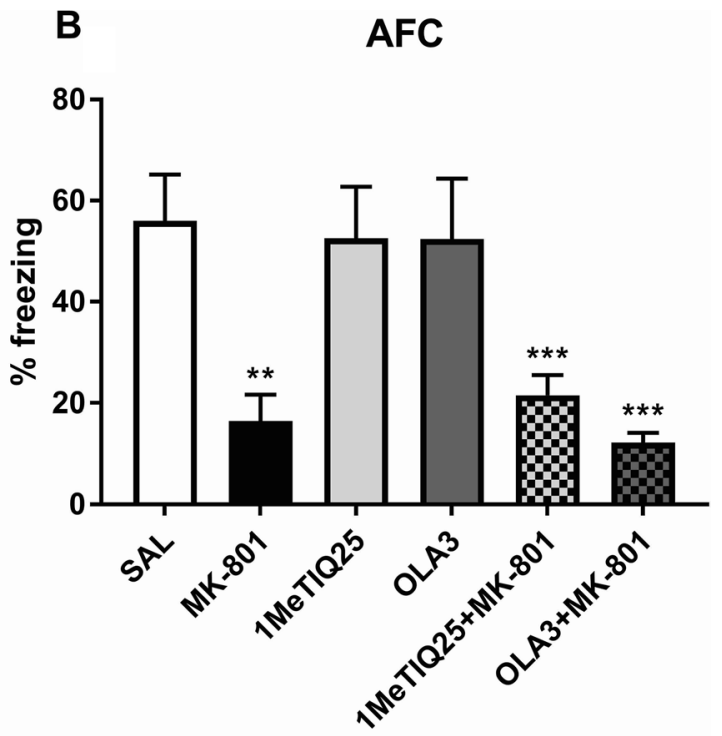

treatment
Fig. 3 The effect of MK-801 (0.3 mg/kg, sc), acute 1MeTIQ (25 mg/ $\mathrm{kg}$, ip) and olanzapine $(3 \mathrm{mg} / \mathrm{kg}, i p)$ administration on the expression of fear conditioning in the forms of CFC (a) and AFC $\mathbf{b}$ in the testing phase (day 2). The data were analyzed using one-way ANOVA and a post hoc Duncan's MRT. The data are shown as the means \pm SEM
A

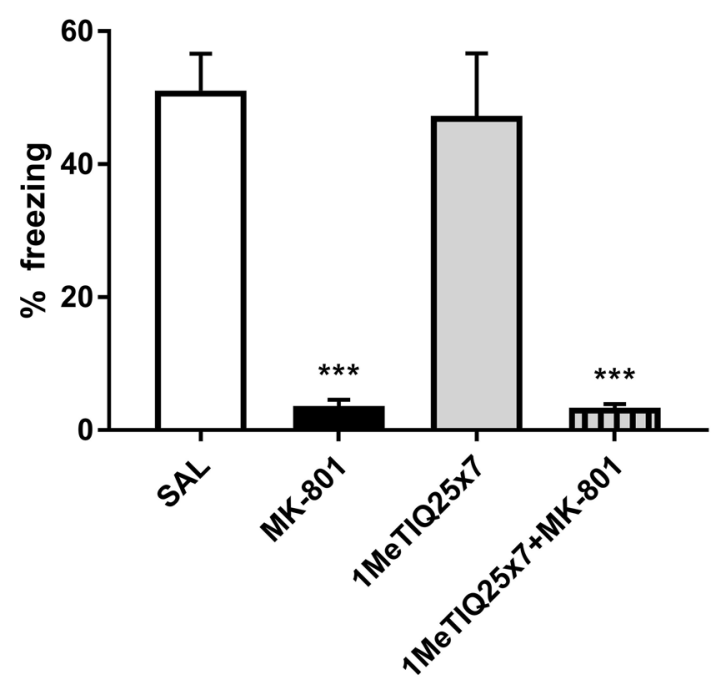

treatment
Fig. 4 The effect of MK-801 (0.3 mg/kg, sc) and chronic (7x) 1MeTIQ (25 mg/kg, ip) administration on the expression of fear conditioning in the forms of $\mathrm{CFC}$ (a) and $\mathrm{AFC} \mathbf{b}$ in the testing phase (day 2). The data were analyzed using two-way ANOVA and a post hoc Duncan's MRT. The data are shown as the means \pm SEM and expressed as a percentage of the session time. $N=8-10$ rats per group. $* p<0.05 ; * * p<0.01 ; * * * p<0.001$ compared to the control (saline) group. Significant changes were not observed when compared to the MK-801-treated group

B

AFC

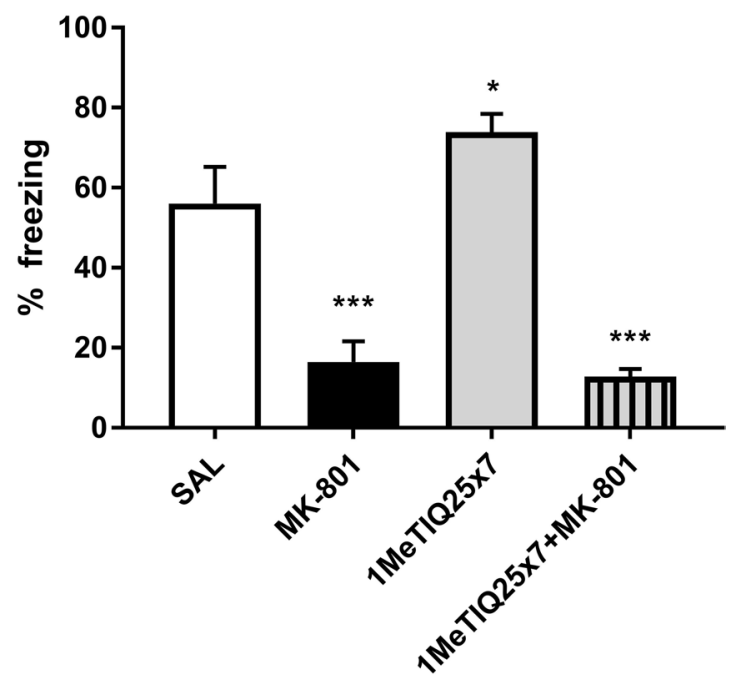

treatment and expressed as a percentage of the session time. $N=8-10$ rats per group. ${ }^{*} p<0.05 ; * * p<0.01 ; * * * p<0.001$ compared to the control (SAL) group. Significant changes were not observed when compared to the MK-801-treated group 


\section{Chronic treatment with 1MeTIQ_contextual fear conditioning (CFC)}

Two-way ANOVA revealed a significant effect of MK-801 $\left(F_{1,32}=87.9, p<0.001\right)$ on $\%$ freezing time in the CFC. The same analysis showed no significant effect $\left(F_{1,32}=0.17\right.$, $p=0.68)$ of chronic 1MeTIQ on measured parameter. The interaction of both treatments had no significant effect $\left(F_{1,32}=0.13, p=0.72\right)$ on $\%$ freezing time. Post hoc tests showed a significant $(p<0.001)$ decrease in \%freezing time in the CFC after MK-801 treatment. Duncan's MRT showed a significant $(p<0.001)$ decrease in \% freezing time in the combined treatment (chronic 1MeTIQ and acute MK-801) (Fig. 4a).

\section{Chronic treatment with 1MeTIQ_-auditory fear conditioning (AFC)}

Two-way ANOVA showed a significant effect $\left(F_{1,31}=84.28\right.$, $p<0.001)$ of MK-801 on \% freezing time. However, the same analysis showed no significant effect $\left(F_{1,31}=1.66\right.$, $p=0.21$ ) of chronic 1MeTIQ on $\%$ freezing time in AFC. The interaction of both treatments had no significant effect $\left(F_{1,32}=3.88, p=0.06\right)$ on $\%$ freezing time. Post hoc tests revealed a significant $(p<0.001)$ decrease in $\%$ freezing time in MK-801-treated animals. Chronic administration of $1 \mathrm{MeTIQ}$ alone produced a significant $(p<0.05)$ increase in $\%$ freezing time. Treatment with both chronic 1MeTIQ and acute MK-801 significantly $(p<0.001)$ decreased \% freezing time (Fig. 4b).

A

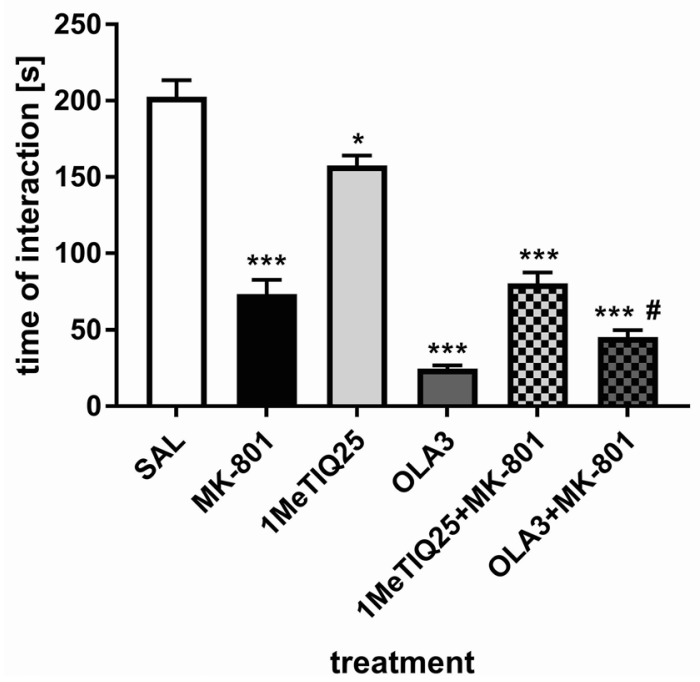

Fig. 5 The effect of MK-801 (0.3 mg/kg, sc), acute 1MeTIQ (25 mg/ $\mathrm{kg}$, ip) and olanzapine (3 $\mathrm{mg} / \mathrm{kg}$, ip) administration on the duration of social interaction (a) and number of social interactions $\mathbf{b}$ in the SIT. The data were analyzed using one-way ANOVA and a post hoc Dun-

\section{Social interaction test}

\section{Acute treatment with $1 \mathrm{MeTIQ}$}

Interaction time One-way ANOVA revealed a significant $\left(F_{5,48}=90.77, p<0.001\right)$ effect of applied treatment on the time of social interaction. Post hoc tests showed a significant $(p<0.001)$ decrease in the amount of social interaction time after MK-801 treatment. A single dose of 1MeTIQ significantly $(p<0.05)$ reduced the amount of time of social interaction when compared to saline. In olanzapine-treated animals, a strong reduction in the amount of interaction time was observed $(p<0.001)$. In animals treated with both $1 \mathrm{MeTIQ}$ and MK-801, the amount of social interaction time was significantly $(p<0.001)$ decreased when compared to saline. Animals treated with both olanzapine and MK-801 showed a significantly decreased amount of social interaction time compared to both saline and MK-801 animals ( $p<0.001$ and $p<0.05$, respectively) (Fig. 5a).

No. of interactions Statistical analysis showed a significant $\left(F_{5,48}=43.71, p<0.001\right)$ effect of the treatment on the number of social interactions. Post hoc analysis revealed a decrease in the number of social incidents after MK-801, $1 \mathrm{MeTIQ}$, or olanzapine $(p<0.001)$ administration compared to saline. A similar effect was observed in the group treated with both 1MeTIQ and MK-801. Treatment with olanzapine and MK-801 combined significantly lowered the number of social interactions compared to both the control

\section{B}

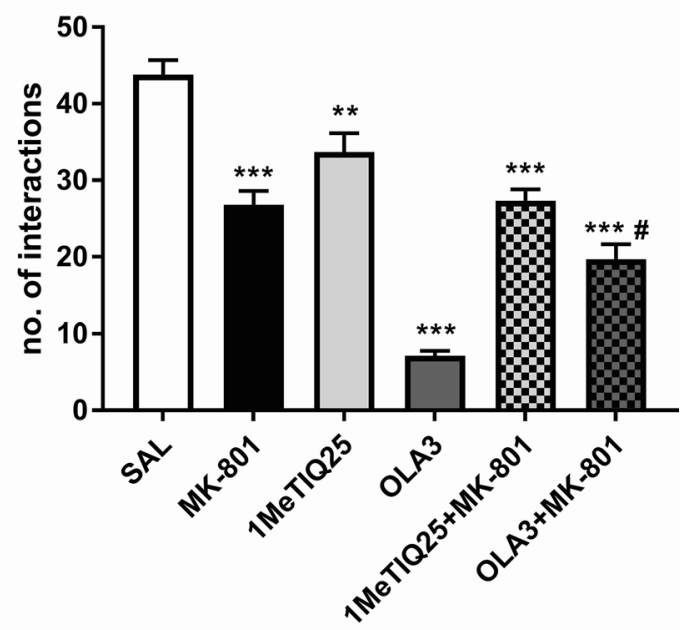

treatment

can's MRT. The data are shown as the means \pm SEM. $N=8-10$ rats per group. $* p<0.05$; ** $p<0.01$; *** $p<0.001$ compared to the control (SAL) group. ${ }^{\#} p<0.05 ;{ }^{\# \#} p<0.01 ;{ }^{\# \#} p<0.001$ when compared to the MK-801-treated group 
and MK-801 groups ( $p<0.001$ and $p<0.05$, respectively) (Fig. 5b).

\section{Chronic treatment with 1 MeTIQ}

Interaction time Two-way ANOVA showed a significant effect of MK-801 $\left(F_{1,17}=58.40, p<0.001\right)$, chronic 1MeTIQ $\left(F_{1,17}=100.77, p<0.001\right)$ or the interaction of both treatments $\left(F_{1,17}=38.04, p<0.001\right)$ on the time of social interaction. Post hoc tests revealed a significant decrease in the amount of interaction time $(p<0.001)$ after MK-801 or chronic 1MeTIQ administration. In the combined group, chronic 1MeTIQ given together with MK-801 caused a significant decrease in the amount of social interaction time when compared to both control $(p<0.001)$ and MK-801-treated animals $(p<0.05)$ (Fig. 6a).

No. of interactions Two-way ANOVA showed a significant effect of MK-801 $\left(F_{1,17}=17.62, p<0.001\right)$, chronic 1MeTIQ $\left(F_{1,17}=51.71, p<0.001\right)$ or the interaction of both treatments $\left(F_{1,17}=7.44, p<0.05\right)$ on the number of social interactions in the behavioral test. Duncan's MRT revealed a significant decrease in the number of social interactions after MK-801 treatment or chronic 1MeTIQ treatment (both $p<0.001)$. Chronic 1MeTIQ administered together with MK-801 caused a significant depletion of social interactions compared to both the saline $(p<0.001)$ and MK-801 $(p<0.01)$ groups (Fig. 6b).

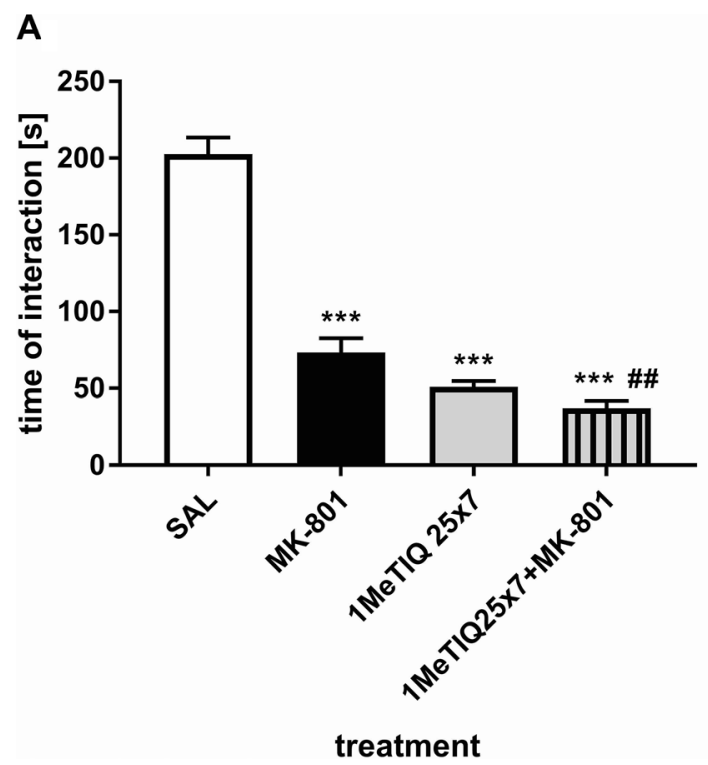

Fig. 6 The effect of MK-801 (0.3 mg/kg, sc) and chronic (7x) $1 \mathrm{MeTIQ}(25 \mathrm{mg} / \mathrm{kg}$, ip) administration on the duration of social interaction (a) and number of social interactions $\mathbf{b}$ in the SIT. The data were analyzed using two-way ANOVA and a post hoc Duncan's

\section{Discussion}

The main point of the presented results was connected with data obtained in neurochemical studies and demonstrated that $1 \mathrm{MeTIQ}$ inhibits the MK-801-induced reduction in DA levels in the Fcx and increases 5-HT concentration. There is evidence that acute administration of NMDA receptor antagonists, such as MK-801 or ketamine, increases DA release in the Fcx and striatum [31, 32]. Our previous in vivo microdialysis study confirmed an increase in DA release in the Fcx caused by systemic injection of MK-801 [33], but in the present ex vivo study, we observed a significant decrease in the tissue concentration of DA, especially in the Fcx, after MK-801 administration, perhaps suggesting its release to the extracellular space. Interestingly, this effect was reversed by both single and multiple administrations of 1MeTIQ; DA levels were restored to just above the control level (Tables 2, 4). An enhancement of DAergic and NAergic transmission in the Fcx can effectively reverse impaired cognition and flexibility in schizophrenia. Therefore, systemic administration of mazindol (an inhibitor of DA and NA reuptake) showed beneficial effects on deficits in the attentional set-shifting task [34]. Some results have indicated that D2 receptors are involved in working memory, and their activation leads to protection against social withdrawal $[35,36]$. Olanzapine acts as a D2 receptor antagonist. Some authors point out that DA receptor antagonists such as haloperidol or clozapine significantly reduce locomotor activity [37, 38],

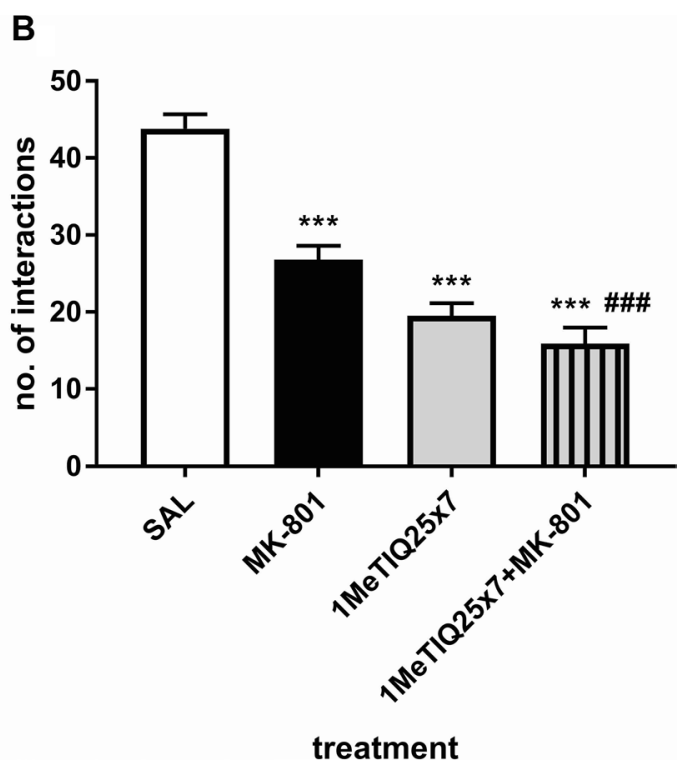

MRT. The data are shown as the means \pm SEM. $N=8-10$ rats per group. ${ }^{*} p<0.05 ; * * p<0.01 ; * * * p<0.001$ compared to the control

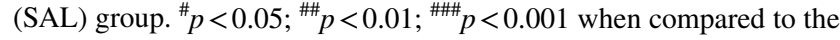
MK-801-treated group 
and such action may mask any potential inhibitory effects of these compounds on FM. Both 1MeTIQ and olanzapine also reduced the locomotor activity of rats. If the animals have reduced motor skills, the number and duration of social contacts is automatically reduced. Therefore, based on these tests, we are not able to determine whether the tested compounds reverse MK-801-induced social and cognitive deficits. Our results confirm data from other authors that olanzapine did not antagonize MK-801-induced deficit

$s$ in social interaction [39]. The mechanism of action of olanzapine is very unclear, and some authors emphasize that olanzapine counteracts the decrease in BDNF levels caused by MK-801 [40]. A similar effect was observed in patients with schizophrenia [41]. However, other studies show no effect of olanzapine on BDNF levels [42, 43].

$1 \mathrm{MeTIQ}$ acts as a partial agonist of DA receptors [20]. In addition, 1MeTIQ possesses a low affinity for NMDA receptors and binds to the glycine site [19]. The present results indicated that a single injection of 1MeTIQ does not interfere with the social interaction of rats. When given together with MK-801, it causes a synergistic effect leading to larger deficits. Perhaps this effect is due to the influence of both compounds on NAergic transmission in the limbic area, especially the Fcx (Table 3). It is important to mention that dysregulation of the NAergic system may play an important role in both the negative and positive symptoms of schizophrenia. It was observed in clinical studies that NA was elevated in the blood plasma as well as in the cerebrospinal fluid of patients with schizophrenia [44, 45]. Interestingly, much research evidence indicates the essential participation of NA and its receptors $(\alpha 1, \alpha 2, \beta)$ in memory function and social interactions, which may play opposite roles in these activities [46, 47].

Other data suggest that an important contribution to the action of antipsychotic drugs on cognitive symptoms of schizophrenia is the balance in activity between the 5-HT1A and DA D2 receptors [48]. MK-801-induced deficits in recognition memory and SIT are associated with the 5-HT1A receptor [49, 50]. 1MeTIQ (given alone or combined with MK-801) significantly increased the concentration of 5-HT in the Fcx and hippocampus (Tables 3, 5). For that reason, we expected a therapeutic effect of 1MeTIQ in these behavioral tests. As we demonstrated earlier, an acute dose of 1MeTIQ decreased locomotor activity in rats and completely inhibited the locomotor hyperactivity induced by MK-801 [33]. 1MeTIQ antagonized some neurochemical and behavioral effects of MK-801, but it did not reverse the behavioral disorders caused by MK- 801 in the FM and SIT tests. Similarly, as has been previously demonstrated, 1MeTIQ did not improve sensorimotor gating deficits induced by MK-801 [33].

In this study, we set out to determine the effects of 1MeTIQ on FM and social recognition deficits induced by the noncompetitive NMDA receptor antagonist MK-801. It is well documented that hypoactivation of the glutamatergic system is a key mechanism underlying schizophrenia, and NMDA receptor involvement has been confirmed for FM [51] and social activity in rats [12, 39]. Fear conditioning provides an elementary form of learning through which animals learn to predict an aversive stimulus and learn to react appropriately to a threat [51], while deficits measured in the SIT mimic negative symptoms of schizophrenia in rats.

In our study, acute administration of MK-801 disturbed both FM and social interaction (Figs. 3, 4, 5, 6), which is consistent with the results obtained by other authors [39, 52, 53].

The results obtained in the FM test indicated that a single 1MeTIQ administration does not cause deficits in the fear conditioning test for either the CFC or AFC (Fig. 3a, b). At the same time, in the combined group, 1MeTIQ did not reverse the effects caused by MK-801 administration (Fig. 3a, b). Olanzapine given alone produced deficits in the CFC (Fig. 3a), and when given in conjunction with MK-801, it did not inhibit MK-801-induced deficits in either CFC and AFC (Fig. 3a, b). There are discrepancies in the literature regarding the effects of olanzapine: Siemiątkowski et al. [54] indicated that acute treatment with olanzapine decreased preshock contextual vocalizations and tended to diminish postshock vocalization; Milstein et al. [55] showed that chronic treatment with olanzapine caused specific deficits in extinction of fear conditioning and working memory, while Mead et al. [56] reported that olanzapine alleviates a variety of fear-related responses. Inoue and coworkers [57] found that olanzapine and clozapine reduced contextual fear in a dose-dependent manner. It seems that such different effects of olanzapine are caused by different protocols and doses of administration. Interestingly, chronic administration of 1MeTIQ did not change the behavior of the rats in the CFC but significantly $(p<0.05)$ increased freezing in the AFC among treated rats compared to the control group (Fig. 4b). There is evidence that elevated levels of synaptic DA result in reduced CFC (see review [58]). For this reason, different dopaminergic drugs have been examined for FM: bupropion (a DA and NA reuptake inhibitor) and aripiprazole (a partial D2 and 5-HT1 A receptor agonist) reduce the retrieval of contextual fear; in contrast, haloperidol has no effect $[57,59,60]$.

The effect of 1MeTIQ and olanzapine was also demonstrated in another behavioral test- the SIT. Our knowledge of the neural mechanisms underlying social behavior is limited. Pharmacological modulation of social interaction has revealed that psychomotor stimulants such as amphetamine and methylphenidate profoundly inhibit social play through a NAergic mechanism of action in the Fcx [61-64]. More recently, Achterberg et al. [65] investigated the different effects of DA and NA in social play in rats, determining that 
DA was more strongly associated with motivation for play, while enhanced NA negatively modulated both motivation and expression of social play. Furthermore, it was determined that infusion of methylphenidate and atomoxetine (NA reuptake inhibitors) into the prefrontal and limbic brain areas inhibited social behavior via increased NAergic activity [64]. In contrast, Kohli and coworkers demonstrated in a microdialysis study that oxytocin promotes social behavior by selectively elevating DA overflow in the nucleus accumbens but not in the Fcx [66]. Our study showed that an acute dose of 1MeTIQ slightly reduced $(p<0.05)$ both the number and duration of social interactions (Fig. 5a, b), and in the same study, 1MeTIQ did not reverse the social withdrawal induced by a single dose of MK-801. In the same experiment, a single dose of olanzapine strongly reduced both the number and duration of social interactions $(p<0.001)$, whereas olanzapine coadministered with MK-801 potentiated NMDA antagonist-induced disorder (Fig. 5a, b). Moreover, chronic administration of 1MeTIQ (for 7 days) induced social recognition deficits $(p<0.001)$ similar to those caused by a single administration of MK-801 (Fig. 6a, b). Multiple 1MeTIQ injections combined with a single dose of MK-801 increased NMDA antagonist-induced disorders (Fig. 6a, b). The results above revealed that neither 1MeTIQ nor olanzapine reversed MK-801-induced deficits in social interaction in rats. Atypical antipsychotics are considered effective in treating positive, negative, and cognitive symptoms, but treatment efficacy varies across the different pharmacological agents [67-70]. For example, treatment with the atypical neuroleptic olanzapine or risperidone did not reverse negative symptoms of schizophrenia either in the clinic [71] or in an animal model: MK-801-induced deficits in social recognition in rats [39]. We must remember that preclinical studies are conducted in animal models. All animal models are imperfect and reflect human diseases only to a limited extent. This applies in particular to mental illnesses, which are very difficult to model, e.g., depression or schizophrenia.

\section{Conclusion}

Our neurochemical studies showed that 1MeTIQ completely antagonized the MK-801-induced reduction in DA levels in the Fcx and significantly increased the 5-HT concentration in both investigated structures. On the other hand, the behavioral results demonstrated that neither 1MeTIQ nor olanzapine antagonized negative symptoms (as shown by the FM and SIT) in an MK-801-induced model of schizophrenia. Therefore, we would like to investigate the essential role of NA in the Fcx in deepening the negative symptoms of schizophrenia. Moreover, the main pharmacological hypotheses focusing on DA system stabilization and DA-serotonin system interactions as the probable mechanism ameliorating negative symptoms of schizophrenia were not fully confirmed in the behavioral tests (FM and SIT) that were used.

Acknowledgements The authors would like to thank Maria Kafel for her excellent technical assistance and Aneta Kozioł for the chemical synthesis of $1 \mathrm{MeTIQ}$.

Author contributions AW: designed the study; MB, AC, and IMM: performed the behavioral experiments and collected the data; $M \dot{Z}$ and KM: performed biochemical experiments and collected the data; AW and LAM: analyzed the data; MB, AW, and LAM wrote the paper. All authors approved the final manuscript and submission.

Funding This study was financially supported through a grant from the National Science Centre Grant no. 2017/25/B/NZ7/01096 and statutory funds from the Maj Institute of PAS, Krakow, Poland. Open access publishing of this article was funded by the Ministry of Science and Higher Education under the agreement No. 879/P-DUN/2019.

\section{Compliance with ethical standards}

Conflict of interest The authors declare that the research was conducted in the absence of any commercial or financial relationships that could be construed as a potential conflict of interest.

Open Access This article is licensed under a Creative Commons Attribution 4.0 International License, which permits use, sharing, adaptation, distribution and reproduction in any medium or format, as long as you give appropriate credit to the original author(s) and the source, provide a link to the Creative Commons licence, and indicate if changes were made. The images or other third party material in this article are included in the article's Creative Commons licence, unless indicated otherwise in a credit line to the material. If material is not included in the article's Creative Commons licence and your intended use is not permitted by statutory regulation or exceeds the permitted use, you will need to obtain permission directly from the copyright holder. To view a copy of this licence, visit http://creativecommons.org/licenses/by/4.0/.

\section{References}

1. $\mathrm{Xu} \mathrm{Y,} \mathrm{Ren} \mathrm{J,} \mathrm{Ye} \mathrm{H.} \mathrm{Association} \mathrm{between} \mathrm{variations} \mathrm{in} \mathrm{the} \mathrm{dis-}$ rupted in schizophrenia 1 gene and schizophrenia: a meta-analysis. Gene. 2018;651:94-9.

2. Holt DJ, Coombs G, Zeidan MA, Goff DC, Milad MR. Failure of neural responses to safety cues in schizophrenia. Arch Gen Psychiatry. 2012;69:893-903.

3. Chocyk A, Przyborowska A, Makuch W, Majcher-Maślanka I, Dudys D, Wędzony K. The effect of early-life adversity on fear memories in adolescent rats and their persistence into adulthood. Behav Brain Res. 2014;265:161-72.

4. Blanchard RJ, Blanchard DC. Defensive reactions in the albino rat. Learn Motiv. 1971;2:351-62.

5. Bolles RC. Specifies-specific defense reactions and avoidance learning. Psychol Rev. 1970;77:32-48.

6. Rung JP, Carlsson A, Markinhuhta KR, Carlsson ML. The dopaminergic stabilizers (-)-OSU6162 and ACR16 reverse (+)-MK801 -induced social withdrawal in rats. Prog Neuropsychopharmacol Biol Psychiatry. 2005;29:833-9.

7. Geyer M, Moghaddam B. Animal models relevant to schizophrenia disorders. In: Davis KL, Charney C, Coyle JT, Nemeroff $\mathrm{C}$, editors. Neuropsychopharmacology: the fifth generation of 
progress. Philadelphia: Lippincott Williams and Wilkins; 2002. p. 689-701.

8. Gururajan A, Taylor DA, Malone DT. Current pharmacological models of social withdrawal in rats: relevance to schizophrenia. Behav Pharmacol. 2010;21:690-709.

9. Bubenikova-Valesova V, Stuchlik A, Svoboda J, Bures J, Vales $\mathrm{K}$. Risperidone and ritanserin but not haloperidol block effect of dizocilpine on the active allothetic place avoidance task. Proc Natl Acad Sci USA. 2008;105:1061-6.

10. Stuchlik A, Rezacova L, Vales K, Bubenikova V, Kubik S. Application of a novel Active Allothetic Place Avoidance task (AAPA) in testing a pharmacological model of psychosis in rats: comparison with the Morris Water Maze. Neurosci Lett. 2004;366:162-6.

11. Van der Staay FJ, Rutten K, Erb C, Blokland A. Effects of the cognition impairer MK-801 on learning and memory in mice and rats. Behav Brain Res. 2011;220:215-29.

12. Gururajan A, Taylor DA, Malone DT. Cannabidiol and clozapine reverse MK-801-induced deficits in social interaction and hyperactivity in Sprague-Dawley rats. J Psychopharmacol. 2012;26:1317-32.

13. Nickerson CA, Brown AL, Yu W, Chun Y, Blenn MJ. Prenatal choline supplementation attenuates MK-801-induced deficits in memory, motor function, and hippocampal plasticity in adult male rats. Neuroscience. 2017;361:116-28.

14. Oh HK, Jeon SJ, Lee S, Lee HE, Kim E, Park SJ, et al. Swertisin ameliorates pre-pulse inhibition deficits and cognitive impairment induced by MK-801 in mice. J Psychopharmacol. 2017;31:250-9.

15. Lee J, Amorim FE, Cassini LF, Amaral OB. Different temporal windows for CB1 receptor involvement in contextual fear memory destabilisation in the amygdala and hippocampus. PLoS ONE. 2019;14:e0205781.

16. Del Fabro L, Delvecchio G, D'Agostino A, Brambilla P. Effects of olanzapine during cognitive and emotional processing in schizophrenia: a review of functional magnetic resonance imaging findings. Hum Psychopharmacol. 2019;34:e2693.

17. Nagai $\mathrm{N}$, Watanabe $\mathrm{K}$. Olanzapine. Nihon Rinsho. 2013;71:666-72.

18. Yamakawa T, Kotake Y, Fujitani M, Shintani H, Makino Y, Ohta S. Regional distribution of Parkinsonism-preventing endogenous tetrahydroisoquinoline derivatives and an endogenous Parkinsonism-preventing substance-synthesizing enzyme in monkey brain. Neurosci Lett. 1999;276:68-70.

19. Antkiewicz-Michaluk L, Lazarewicz JW, Patsenka A, Kajta M, Zieminska E, Salinska E, et al. The mechanism of 1,2,3,4-tetrahydroisoquinolines neuroprotection: the importance of free radicals scavenging properties and inhibition of glutamate-induced excitotoxicity. J Neurochem. 2006;97:846-56.

20. Antkiewicz-Michaluk L, Filip M, Michaluk J, Romańska I, Przegaliński E, Vetulani J. An endogenous neuroprotectant substance, 1-methyl-1,2,3,4-tetrahydroisoquinoline (1MeTIQ), prevents the behavioral and neurochemical effects of cocaine reinstatement in drug-dependent rats. J Neural Transm (Vienna). 2007;114:307-17.

21. Patsenka A, Antkiewicz-Michaluk L. Inhibition of rodent brain monoamine oxidase and tyrosine hydroxylase by endogenous compounds-1,2,3,4-tetrahydro-isoquinoline alkaloids. Pol J Pharmacol. 2004;56:727-34.

22. Wąsik A, Romańska I, Zelek-Molik A, Nalepa I, AntkiewiczMichaluk L. The protective effect of repeated 1MeTIQ administration on the lactacystin-induced impairment of dopamine release and decline in TH level in the rat brain. Neurotoxic Res. 2018;34:706-16.

23. Wąsik A, Romańska I, Antkiewicz-Michaluk L. Important role of 3-methoxytyramine in the inhibition of cocaine sensitization by 1-methyl-1,2,3,4-tetrahydroisoquinoline: an in vivo microdialysis study. Pharmacol Rep. 2010;62:983-97.
24. Wąsik A, Białoń M, Żarnowska M, Antkiewicz-Michaluk L. Comparison of the effects of 1MeTIQ and olanzapine on performance in the elevated plus maze test and monoamine metabolism in the brain after ketamine treatment. Pharmacol Biochem Behav. 2019;181:17-27.

25. Ginos JZ, Doroski D. Dopaminergic antagonists: effects of 1,2,3,4-tetrahydroisoquinoline and its $N$-methyl and $N$-propyl homologs on apomorphine- and L-dopa-induced behavioral effects in rodents. J Pharmacol Exp Ther. 1979;209:79-86.

26. Vetulani J, Nalepa I, Antkiewicz-Michaluk L, Sansone M. Opposite effect of simple tetrahydroisoquinolines on amphetamine- and morphine-stimulated locomotor activity in mice. J Neural Transm (Vienna). 2001;108:513-26.

27. Vetulani J, Antkiewicz-Michaluk L, Nalepa I, Sansone M. A possible physiological role for cerebral tetrahydroisoquinolines. Neurotox Res. 2003;5:147-55.

28. Wilson CA, Koenig JI. Social interaction and social withdrawal in rodents as readouts for investigating the negative symptoms of schizophrenia. Eur Neuropsychopharmacol. 2014;24:759-73.

29. Białoń M, Żarnowska M, Antkiewicz-Michaluk L, Wąsik A. Pro-cognitive effect of 1 MeTIQ on recognition memory in the ketamine model of schizophrenia in rats: the behavioural and neurochemical effects. Psychopharmacology. 2020;237:1577-93.

30. Kamińska K, Rogóż Z. The effect of combined treatment with risperidone and antidepressants on the MK-801-induced deficits in the social interaction test in rats. Pharmacol Rep. 2015;67:1183-7.

31. Miller DW, Abercrombie ED. Effects of MK-801 on spontaneous and amphetamine-stimulated dopamine release in striatum measured with in vivo microdialysis in awake rats. Brain Res Bull. 1996;40:57-62.

32. Jentsch JD, Tran A, Le D, Youngren KD, Roth RH. Subchronic phencyclidine administration reduces mesoprefrontal dopamine utilization and impairs prefrontal cortical-dependent cognition in the rat. Neuropsychopharmacology. 1997;17:92-9.

33. Pietraszek M, Michaluk J, Romańska I, Wąsik A, Gołembiowska K, Antkiewicz-Michaluk L. 1-Methyl-1,2,3,4-tetrahydroisoquinoline antagonizes a rise in brain dopamine metabolism, glutamate release in frontal cortex and locomotor hyperactivity produced by MK-801 but not the disruptions of prepulse inhibition, and impairment of working memory in rat. Neurotox Res. 2009;16:390-407.

34. Nikiforuk A, Głembiowska K, Popik P. Mazindol attenuates ketamine-induced cognitive deficit in the attentional set shifting task in rats. Eur Neuropsychopharmacol. 2010;20:37-48.

35. Kimberg DY, Aguirre GK, Lease J, D'Esposito M. Cortical effects of bromocriptine, a D-2 dopamine receptor agonist, in human subjects, revealed by fMRI. Hum Brain Mapp. 2001;12:246-57.

36. Dyck B, Guest K, Sookram C, Basu D, Johnson R, Mishra RK. PAOPA, a potent analogue of Pro-Leu-glycinamide and allosteric modulator of the dopamine D2 receptor, prevents NMDA receptor antagonist (MK-801)-induced deficits in social interaction in the rat: implications for the treatment of negative symptoms in schizophrenia. Schizophr Res. 2011;125:88-92.

37. Coward DM. General pharmacology of clozapine. Br J Psychiatry Suppl. 1992;17:5-11.

38. Heath FC, Jurkus R, Bast T, Pezze MA, Lee JL, Voigt JP, et al. Dopamine D1-like receptor signalling in the hippocampus and amygdala modulates the acquisition of contextual fear conditioning. Psychopharmacology. 2015;232:2619-29.

39. Deiana S, Watanabe A, Yamasaki Y, Amada N, Kikuchi T, Stott C, et al. MK-801-induced deficits in social recognition in rats: reversal by aripiprazole, but not olanzapine, risperidone, or cannabidiol. Behav Pharmacol. 2015;26:748-65.

40. Fumagalli F, Molteni R, Roceri M, Bedogni F, Santero R, Fossati $\mathrm{C}$, et al. Effect of antipsychotic drugs on brain-derived neurotrophic factor expression under reduced $N$-methyl-D-aspartate receptor activity. J Neurosci Res. 2003;72:622-8. 
41. Rizos EN, Papadopoulou A, Laskos E, Michalopoulou PG, Kastania A, Vasilopoulos D, et al. Reduced serum BDNF levels in patients with chronic schizophrenic disorder in relapse, who were treated with typical or atypical antipsychotics. World J Biol Psychiatry. 2010;11:251-5.

42. Kudlek Mikulic S, Mihaljevic-Peles A, Sagud M, Bajs Janovic M, Ganoci L, Grubisin J, et al. Brain-derived neurotrophic factor serum and plasma levels in the treatment of acute schizophrenia with olanzapine or risperidone: 6-week prospective study. Nord J Psychiatry. 2017;71:513-20.

43. Valvassori SS, Stertz L, Andreazza AC, Rosa MI, Kapczinski F, Streck EL, et al. Lack of effect of antipsychotics on BNDF and NGF levels in hippocampus of Wistar rats. Metab Brain Dis. 2008;23:213-9.

44. Farley IJ, Price KS, McCullough E, Deck JH, Hordynski W, Hornykiewicz O. Norepinephrine in chronic paranoid schizophrenia: above-normal levels in limbic forebrain. Science. 1978;200:456-8.

45. Kemali D, Del Vecchio M, Maj M. Increased noradrenaline levels in CSF and plasma of schizophrenic patients. Biol Psychiatry. 1982;17:711-7.

46. Hillman KL, Lei S, Doze VA, Porter JE. Alpha-1A adrenergic receptor activation increases inhibitory tone in CA1 hippocampus. Epilepsy Res. 2009;84:97-109.

47. Zhang Z, Cordeiro Matos S, Jego S, Adamantidis A, Séguéla P. Norepinephrine drives persistent activity in prefrontal cortex via synergistic $\alpha 1$ and $\alpha 2$ adrenoceptors. PLoS ONE. 2013;8:e66122.

48. Bruins Slot LA, Kleven MS, Newman-Tancredi A. Effects of novel antipsychotics with mixed $\mathrm{D}(2)$ antagonist/5-HT(1A) agonist properties on PCP-induced social interaction deficits in the rat. Neuropharmacology. 2005;49:996-1006.

49. Hereta M, Kamińska K, Rogóż Z. Co-treatment with antidepressants and aripiprazole reversed the MK-801-induced some negative symptoms of schizophrenia in rats. Pharmacol Rep. 2019;71:768-73

50. Hereta M, Kamińska K, Białoń M, Wąsik A, Lorenc-Koci E, Rogóż Z. Effect of combined treatment with aripiprazole and antidepressants on the MK-801-induced deficits in recognition memory in novel recognition test and on the release of monoamines in the rat frontal cortex. Behav Brain Res. 2020;393:112769.

51. Latusz J, Radaszkiewicz A, Bator E, Wędzony K, Maćkowiak M. Fear memory in a neurodevelopmental model of schizophrenia based on the postnatal blockade of NMDA receptors. Pharmacol Rep. 2017;69:71-6.

52. Cieślik P, Radulska A, Pelikant-Małecka I, Płoska A, Kalinowski L, Wierońska JM. Reversal of MK-801-induced disruptions in social interactions and working memory with simultaneous administration of LY487379 and VU152100 in mice. Int J Mol Sci. 2019;20:2781.

53. Langton JM, Kim JH, Nicholas J, Richardson R. The effect of the NMDA receptor antagonist MK-801 on the acquisition and extinction of learned fear in the developing rat. Learn Mem. 2007;14:665-8.

54. Siemiątkowski M, Maciejak P, Sienkiewicz-Jarosz H, Członkowska AI, Szyndler J, Gryczyńska A, et al. Opposite effect of olanzapine and haloperidol in rat ultrasonic vocalization test. Pol J Pharmacol. 2001;53:669-73.

55. Milstein JA, Elnabawi A, Vinish M, Swanson T, Enos JK, Bailey $\mathrm{AM}$, et al. Olanzapine treatment of adolescent rats causes enduring specific memory impairments and alters cortical development and function. PLoS ONE. 2013;8:e57308.

56. Mead A, Li M, Kapur S. Clozapine and olanzapine exhibit an intrinsic anxiolytic property in two conditioned fear paradigms: contrast with haloperidol and chlordiazepoxide. Pharmacol Biochem Behav. 2008;90:551-62.

57. Inoue T, Tsuchiya K, Koyama T. Effects of typical and atypical antipsychotic drugs on freezing behavior induced by conditioned fear. Pharmacol Biochem Behav. 1996;55:195-201.

58. Stubbendorff C, Stevenson CW. Dopamine regulation of contextual fear and associated neural circuit function. Eur J Neurosci. 2020;112:1-15.

59. Biojone C, Casarotto PC, Resstel LB, Zangrossi H Jr, Guimarães FS, Moreira FA. Anti-aversive effects of the atypical antipsychotic, aripiprazole, in animal models of anxiety. J Psychopharmacol. 2011;25:801-7.

60. Portugal GS, Gould TJ. Bupropion dose-dependently reverses nicotine withdrawal deficits in contextual fear conditioning. Pharmacol Biochem Behav. 2007;88:179-87.

61. Sutton ME, Raskin LA. A behavioral analysis of the effects of amphetamine on play and locomotor activity in the post-weaning rat. Pharmacol Biochem Behav. 1986;24:455-61.

62. Vanderschuren LJMJ, Trezza V, Griffioen-Roose S, Schiepers OJ, Van Leeuwen N, De Vries TJ, et al. Methylphenidate disrupts social play behavior in adolescent rats. Neuropsychopharmacology. 2008;33:2946-56.

63. Achterberg EJM, Trezza V, Siviy SM, Schrama L, Schoffelmeer ANM, Vanderschuren LJMJ. Amphetamine and cocaine suppress social play behavior in rats through distinct mechanisms. Psychopharmacology. 2014;231:1503-15.

64. Achterberg EJM, van Kerkhof LWM, Damsteegt R, Trezza V, Vanderschuren LJMJ. Methylphenidate and atomoxetine inhibit social play behavior through prefrontal and subcortical limbic mechanisms in rats. J Neurosci. 2015;35:161-9.

65. Achterberg EJ, van Kerkhof LW, Servadio M, van Swieten MM, Houwing DJ, Aalderink M, et al. Contrasting roles of dopamine and noradrenaline in the motivational properties of social play behavior in rats. Neuropsychopharmacology. 2016;41:858-68.

66. Kohli S, King MV, Wiliams S, Edwards A, Ballard TM, Steward $\mathrm{LJ}$, et al. Oxytocin attenuates phencyclidine hyperactivity and increases social interaction and nucleus accumbens dopamine release in rats. Neuropsychopharmacology. 2019;44:295-305.

67. Carlsson A, Waters N, Carlsson ML. Neurotransmitter interactions in schizophrenia-therapeutic implications. Biol Psychiatry. 1999;46:1388-95.

68. Meltzer HY. Clinical studies of the mechanism of action of clozapine: the dopamine and serotonin hypothesis of schizophrenia. Psychopharmacology. 1989;99(Suppl):S18-27.

69. Meltzer HY, McGurk SR. The effect of clozapine, risperidone and olanzapine on cognitive function in schizophrenia. Schizophr Bull. 1999;25:233-55.

70. Meltzer HY, Li Z, Kaneda Y, Ichikawa J. Serotonin receptors and their key role in drugs to treat schizophrenia. Prog Neuropsychopharmacol Biol Psychiatry. 2003;27:1159-72.

71. McEvoy JP, Lieberman JA, Stroup TS, Davis SM, Meltzer HY, Rosenheck RA, et al. Effectiveness of clozapine versus olanzapine, quetiapine, and risperidone in patients with chronic schizophrenia who did not respond to prior atypical antipsychotic treatment. Am J Psychiatry. 2006;163:600-10.

Publisher's Note Springer Nature remains neutral with regard to jurisdictional claims in published maps and institutional affiliations. 